Cómo citar este trabajo: Fernández Álvarez, R., Gómez-Gonçalves, A., \& Luengo Ungidos Correo, M. Á. (2019). Aprendiendo a interpretar el territorio: estudio de la fitotoponimia en la provincia de Salamanca. Boletín de la Asociación de Geógrafos Españoles, 82, 2816, 1-33. http://dx.doi.org/10.21138/bage.2816

\title{
Aprendiendo a interpretar el territorio: estudio de la fitotoponimia en la provincia de Salamanca
}

\author{
Learning to understand the territory: a study case \\ of the phytotoponymy from Salamanca province (Spain)
}

\section{Rubén Fernández Álvarez}

rfa@usal.es

\section{Alejandro Gómez-Gonçalves}

algomez@usal.es

\section{Miguel Ángel Luengo Ugidos Correo \\ malu@usal.es}

Departamento de Geografía

Universidad de Salamanca (España)

\section{Resumen}

Uno de los recursos frecuentes en los análisis territoriales ha sido la toponimia. Esta nos ofrece una visión sobre las denominaciones que el ser humano ha otorgado al espacio. Entre los elementos utilizados para singularizar e individualizar el espacio en áreas reconocibles para la población, la vegetación ha sido uno de los más destacados. Los fitotopónimos pueden hacer alusión a especies vegetales que potencialmente podrían desarrollarse en esos lugares, o por el contrario estar refiriéndose a otras que por sus necesidades no tienen cabida. El presente trabajo se centra en la identificación de la correspondencia existente entre la vegetación potencial y los fitotopónimos localizados en los MTN50 que cubren la provincia de Salamanca. La correspondencia existente nos indica que nos encontramos ante un notable agente identificador, al menos, en este territorio. 
Palabras clave: toponimia; fitotopónimo; vegetación potencial; provincia de Salamanca; MTN50.

\begin{abstract}
One of the common resources used in territorial analysis is the study of the toponymy, because it gives us a vision about the denominations that human being has given to the space. Vegetation has been used as an important element to single out and to identify the space in recognizable areas by the local population. The phytotoponymy refers to plants that could potentially develop in these places, or on the contrary, it refers to others that cannot live in this place because of their biological needs. The present work focuses on the correspondence between the potential vegetation and the phytotoponyms located in the maps MTN50 that cover the province of Salamanca. The existing correspondence indicates that we are facing a remarkable identifying agent, at least in this territory.
\end{abstract}

Key words: toponymy; phytotoponym; potential vegetation; province of Salamanca; MTN50.

“De tal modo las palabras llevan la esencia humana de las cosas, que, los que no son nombres propios, los geográficos, los toponímicos, llevan un paisaje, y a las veces, basta sólo, con oír la palabra para adivinar lo que pueda ser la tierra que recibió aquel nombre".

Miguel de Unamuno, El poder de la palabra (1931)

"Los nombres de lugar, tan resistentes a la evolución y mucho más a la desaparición, son los únicos testigos que dan fe, todavía hoy, de la existencia primitiva de plantas silvestres - cultivadas, de especies arbóreas o arbustivas, de arboledas, sotos y montes desgraciadamente desaparecidos, gracias a esos topónimos podemos reconstruir, en parte, el antiguo paisaje vegetal de nuestra Península...".

Llorente y Llorente (2003, p. 84)

\title{
1 Introducción
}

\section{1 ¿Qué es un topónimo?}

En la Geografía española del siglo XX, los estudios sobre el territorio, ya sean de carácter físico o antrópico, comenzaban frecuentemente con una tarea previa e insustituible: la consulta del Mapa Topográfico Nacional 1/50.000 (MTN50). En él, que es el marco cartográfico de referencia y la 
primera fuente a la que se acudía, se sintetizan las características físicas del territorio (topografía, hidrología, etc.) y los usos y ocupaciones del suelo. La toponimia era, por tanto, el elemento del que se partía para analizar las actividades humanas, y tras un primer estudio de los topónimos, se contrastaban con la información obtenida a través del trabajo de campo, tanto su precisión en la localización, como su vigencia en el uso local y, en suma, su utilidad (Tort, 2000). Aunque en las últimas décadas algunos geógrafos han publicado trabajos sobre toponimia, son pocos los que inciden en la importancia que esta tiene para analizar el paisaje de un territorio.

La definición más sencilla de topónimo como "nombre propio de lugar" la proporciona el Diccionario de la Real Academia Española (2016). Por su parte, el Instituto Geográfico Nacional define como topónimo al que se conoce también como nombre geográfico, un nombre propio con el que se identifica una entidad topográfica que habitualmente está formado por un término genérico y otro específico (Alcaraz \& Azcárate, 2005), como por ejemplo Sierra de Béjar. Desde la perspectiva de la lexicología, los topónimos forman parte del grupo de nombres propios onomásticos, ya que en su uso señalan y singularizan sin tener un significado que aporte descripción alguna (Jiménez, 2007).

La aparición de estos nombres propios podría parecer fruto del azar, sin embargo, el topónimo surge para distinguir una zona precisa dentro de un entorno más amplio (Tort, 2001). Es razonable pensar que los topónimos, en origen, eran palabras con un significado perfectamente transparente para los habitantes de un territorio (Gordón, 2011; Sanz \& Villar, 2012). Es decir, el topónimo se convertiría en un indicador de una realidad concreta e individual que se quiere singularizar dentro de un contexto más extenso (Jiménez, 2007; Llorente \& Llorente, 2003). De esta manera, un paraje saldría del anonimato para cristalizar en el tiempo y en el espacio (Riesco, 2010). Este carácter descriptivo confiere a la toponimia un notable interés en cuanto a que puede proporcionar información endógena sobre algunas de las características del paisaje (liménez, 2007; Molina, 2012), pues se trata de datos generados por los habitantes de un determinado territorio y nos permite entender cómo la población local percibía y hablaba del territorio para realizar sus actividades cotidianas en el mismo (Riesco, 2010).

La mayor parte de los topónimos existentes se corresponden con el estrato lingüístico más reciente, como demostró Gordón (2011) en el caso de Andalucía o Román (2011) en su estudio centrado en la fitotoponimia de la provincia de Jaén, realidad que se hacía extensible a todos los territorios donde predomina la lengua española. Las causas que explican esos nombres están muchas veces vinculadas a las características geográficas del entorno (Arroyo, 2010). Por lo tanto, tomando siempre una cierta cautela, los topónimos nos transmitirían una serie de indicios sobre el aspecto pretérito del territorio (Llorente \& Llorente, 2003; Fidalgo \& González, 2015), lo que desde el punto de vista de la geografía nos permitiría realizar un análisis de cierta profundidad sobre una determinada superficie, así como sobre la evolución histórica del paisaje, identificando cuáles han 
sido los usos tradicionales que allí se han desarrollado (Marco, 1985; Tort, 2001; Ordinas y Binimelis, 2013).

Aunque a día de hoy resulte difícil identificar el significado de un topónimo por su propio carácter dinámico (Benítez et al., 2009), parece evidente que, para tener éxito, un topónimo debería hacer referencia a algo que ha existido (Tort, 2000), y que, además, es posible que describiera un elemento llamativo, sobresaliente, diferenciador e individualizador. Es lo que Tort (2003 y 2006) denomina excepcionalidad, y que, junto a la trasparencia y significancia territorial, serían los tres principales atributos de los nombres de lugar. Es decir, que bien por la singularidad del elemento o bien por su abundancia, se habría seleccionado un topónimo para denominar un determinado territorio con unas características diferenciadoras (Molina, 2012).

\subsection{Los fitotopónimos o topónimos de carácter vegetal}

En toponimia se pueden hacer varias clasificaciones atendiendo a su significado: orografía, geología, meteorología... (Molina, 2012). La vegetación es uno de los elementos más llamativos del paisaje, ya que, si la geomorfología o el sustrato geológico no es excesivamente intrincado o peculiar, como en el caso de los berrocales en España (Llorente, 2011), aquella suele ser el factor que más llama la atención del observador debido a la variedad de colores, texturas (García, 1987) e incluso, en determinadas situaciones, olores que introduce en el paisaje, especialmente en las grandes zonas de bosques o de arbustos.

Esta investigación se centrará en el análisis de los topónimos de carácter vegetal (fitotopónimos) para tratar de comprender si estos respondían a la denominación y caracterización de la vegetación existente. Ha sido posible alcanzar este objetivo debido a que una de las principales características de los topónimos es su pervivencia en el tiempo, aspecto este que los convierte en auténticos fósiles lingüísticos (Llorente, 1991; Llorente \& Llorente, 2003). Además, parece lógica la afirmación de Valenzuela (2010) cuando señala que la forma más sencilla de nombrar un lugar era dándole el nombre de alguno de los elementos más destacados del paisaje, por lo que no sería descabellado pensar que los fitotopónimos hicieran referencia a los elementos más destacados del territorio en el pasado.

Al trabajar con los topónimos de origen vegetal podemos conocer la flora que existió en un determinado territorio (Carrillo et al., 2010; Llorente \& Llorente, 2003; García-Villaraco et al., 2011; Molina, 2012; Torres, 2016), los sistemas de explotación empleados en el pasado, así como el grado de conocimiento que los antiguos pobladores tenían de las plantas (Sanz \& González, 2006). Además, estudios como el que Sousa y García-Murillo (2010) desarrollaron en el Parque Nacional de Doñana, señalan que los topónimos referidos a plantas no suelen ser objeto de imprecisiones. Es necesario recordar que hasta bien entrado el siglo XX la sociedad española era eminentemente rural y el contacto con la naturaleza era mucho más constante de lo que es hoy en 
día, por lo que es de suponer que resultaría más sencillo identificar un determinado terreno con el nombre de un topónimo (Marco, 1985). Esta afirmación, cobra especial relevancia cuando nos referimos al ámbito en el que se ha desarrollado esta investigación, la provincia de Salamanca, en la que el uso predominante del terrazgo históricamente ha sido el agro-silvo-pastoril, y a día de hoy, parece existir todavía una notable correspondencia entre los fitotopónimos y la vegetación a la que aluden.

El paso del tiempo y los cambios en los usos del territorio tienen un efecto directo en la toponimia, ya que, en las áreas rurales, la evolución en los sistemas de explotación contribuye a la progresiva desaparición de la toponimia menor (Ingelmo, 2010). García, Martínez y Prieto (2018) pusieron en evidencia cómo la toponimia se ha ido perdiendo en los valles del norte de León debido a la falta de uso de estos apelativos, puesto que la sociedad actual ya no los necesita para desarrollar sus actividades cotidianas en el territorio. Otros trabajos también inciden en esta idea, como el llevado a cabo por Fidalgo y González (2015) en la localidad de Lillo (Toledo), donde las transformaciones humanas del medio natural han provocado que determinados topónimos hayan desaparecido. Además de las pérdidas, en ocasiones se producen sustituciones motivadas por el cambio de uso. Siguiendo esta línea, el trabajo de Doménech y Llorca (2014) hace referencia a las nuevas denominaciones surgidas de las actividades turísticas. Así en esta sociedad actual, globalizada y de carácter urbano, la toponimia con referencias paisajísticas corre el riesgo de desaparecer. Esta situación se ve reforzada también porque las nuevas técnicas de elaboración cartográfica basadas en el uso de los Sistemas de Información Geográfica (SIG) no favorecen que se preste la debida atención a la toponimia menor.

Sin embargo, los topónimos que sí perviven y que, como ya se ha mencionado, actúan como fósiles lingüísticos, permiten reconstruir paisajes naturales y culturales (Marco, 2001; Marco, 2004) que, en muchos casos, han desparecido, como demuestran Membrado-Tena e Iranzo-García (2017) en su estudio sobre la cuenca del río Vinalopó, Sousa y García-Murillo (2010) en su estudio desarrollado en Doñana, y Gordón (2011) en el caso de los fitotopónimos en Andalucía. En este sentido, son los topónimos relativos al medio biótico (flora y fauna) los que parecen más susceptibles de evolucionar a través del tiempo, bien de forma natural, bien por cambios de uso del suelo. Por ejemplo, un fitotopónimo que hace referencia a una comunidad vegetal se mantendrá como identificador para la población local y para su uso en la cartografía, aunque haya desaparecido el elemento que le dio origen. Este es el caso de las transformaciones y permutaciones de los espacios agrarios, especialmente los ganaderos, que favorecen la evolución de la vegetación hacia su estado climácico. Por citar un caso de este tipo, localizamos en la Provincia de Salamanca el pago "Pico de la dehesa", fitotopónimo situado al sur del núcleo de Arapiles, en la Hoja 478 del MTN50. Esta referencia a una dehesa que en su día fue deforestada 
y roturada, está actualmente dedicada a campos de cultivo, demostrando que se mantiene el fitotopónimo aunque el uso agro-silvo-pastoril que le dio el nombre haya desaparecido.

En el supuesto contrario de que exista una recuperación de la vegetación, esta podría actuar como un nuevo identificador de correspondencia (Sancho \& Fidalgo, 2004), aunque muy probablemente no se vaya a utilizar porque en la sociedad urbana contemporánea, las especies y las comunidades vegetales ya no son elementos que se utilicen para denominar al territorio. Solamente cambiaría el topónimo si aparece un nuevo uso que permitiera su identificación por parte de los actuales pobladores o gestores del territorio, como demostró Panareda (2011) en su estudio sobre la fitotoponímia del Montseny. Por otro lado, el reciente estudio de García, Martínez y Prieto (2018) que recoge la experiencia de recuperar los topónimos a partir de la información directa de los actuales habitantes de las comarcas leonesa de Omaña y Luna, ha demostrado que aún es posible recuperar esta toponimia en algunos lugares de nuestro país, ya que esta información se siguió utilizando por los pobladores hasta mediados del siglo pasado, y estas personas aún siguen con vida.

\subsection{La provincia de Salamanca}

Como ya se mencionó, el área objeto de estudio de esta investigación es la provincia de Salamanca (12 350 km²), localizada al suroeste de la Submeseta norte de la Península lbérica, formando parte de la Comunidad Autónoma de Castilla y León (Figura 1). La altitud media provincial está en torno a los 800 m y se encuentra situada en el centro del Macizo Ibérico, espacio este donde son notables los afloramientos de rocas paleozoicas dominados por granitos además de todas las rocas metamórficas que los suelen acompañar (gneis, cuarcitas y pizarras), por lo que no existe una diferenciación edáfica significativa que permita una destacada variedad de la vegetación asociada al $\mathrm{pH}$ del suelo. Es decir, los únicos suelos que en la provincia contienen más carbonatos son los agrícolas del noreste (comarcas de Salamanca - La Armuña- y Peñaranda), vinculados con las llanuras aluviales del centro de la cuenca del Duero.

Realmente son las condiciones climáticas las que van a determinar una primera diferenciación de formaciones vegetales, tanto desde el punto de vista de las precipitaciones como de las temperaturas. Se puede hablar, por tanto, de un domino genérico del encinar (Quercus ilex subsp. ballota) cuando las precipitaciones anuales son inferiores a $600 \mathrm{~mm}$ y, cuando se supera esta cantidad, del melojar (Quercus pyrenaica). Esta última formación, como se verá más adelante (Figura 10), es la que fragmenta de NNW a SSE el dominio de la encina, coincidiendo con la divisoria de aguas entre el río Tormes y el río Águeda, y con un incremento sensible de la cantidad de precipitación recibida al año. En los márgenes de la misma encontramos con frecuencia bosques mixtos de encinas y robles (incluso quejigos, Quercus faginea) acompañados por sus respectivas orlas espinosas. 


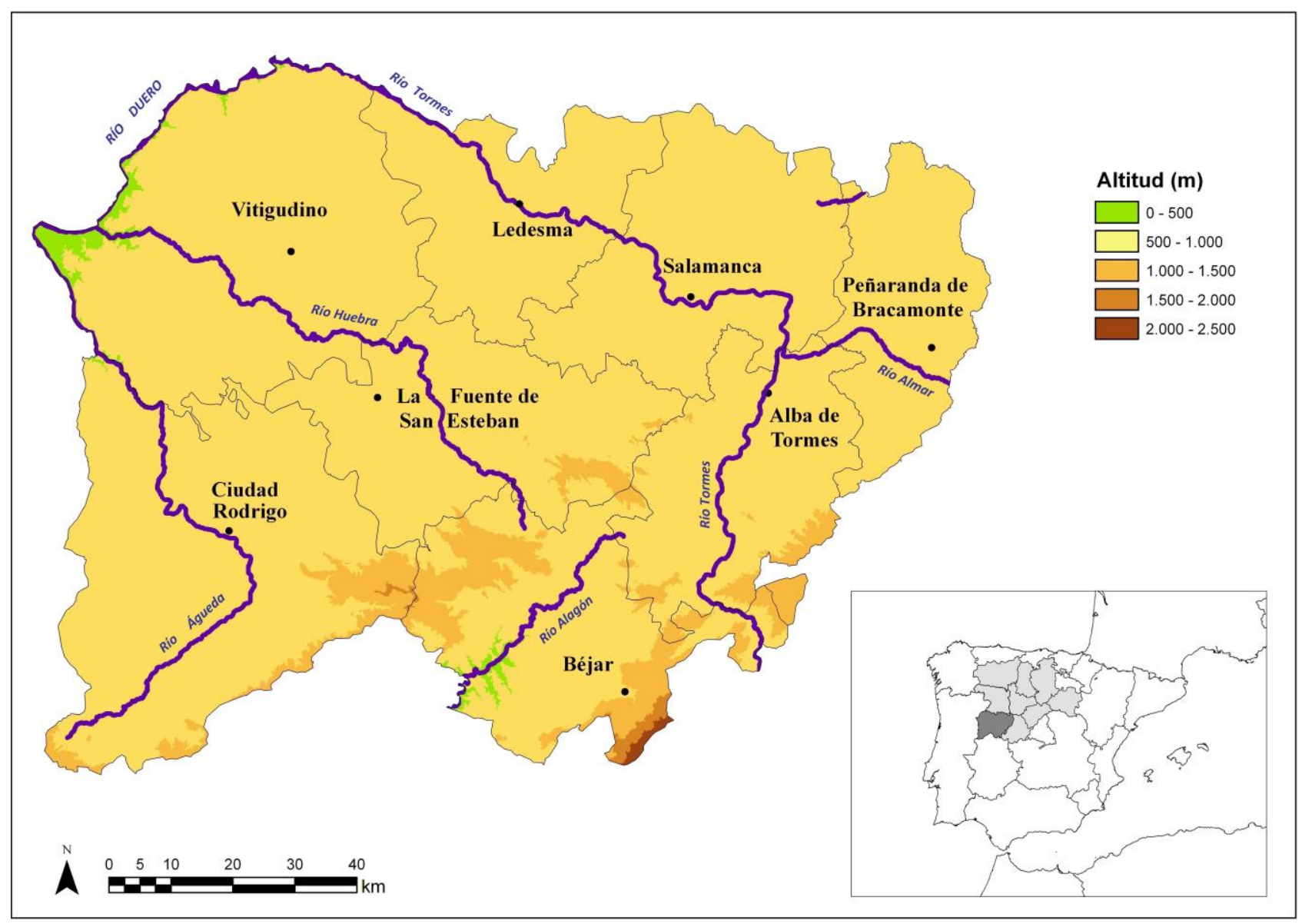

Fuente: elaboración propia a partir de la base cartográfica del IGN

Desde el punto de vista térmico, aunque tenga poca entidad superficial con respecto al total provincial, hay que destacar la peculiaridad climática de Los Arribes del Duero. Se trata del encajamiento del río cuando hace frontera con Portugal a una altitud de tan sólo 116 m en Saucelle, donde se registra una temperatura media anual de $17^{\circ} \mathrm{C}$, lo que favorece la presencia de los acebuches (Olea europaea) y de otras especies termófilas (por ejemplo, el almez u hojaranzo, Celtis australis) que en el espacio agrario han sido sustituidas por cultivos propios del sur peninsular que no soportan las heladas (naranjos y demás cítricos, así como cerezos, caquis y otros árboles frutales). Además de esta singularidad, conviene citar que, en esta comarca, a la benevolencia del clima se le une lo escarpado de la topografía, lo que favorece la presencia de suelos sueltos, arenosos y poco desarrollados, con numerosos afloramientos rocosos (berrocales), lo cual deriva en la presencia de una formación edafoxerófila muy singular y de alto valor ecológico como es el enebral de Juniperus oxycedrus.

Finalmente, las sierras del sur de la provincia (Béjar, Francia, Gata), que se integran en la Cordillera Central, introducen una variabilidad topográfica que permite una diversidad vegetal a medida que cambian las condiciones orográficas locales, especialmente las de exposición, pero siempre dentro 
de los dominios del encinar y del melojar. En resumen, según las últimas versiones de la clasificación bioclimática de Rivas-Martínez (2011), la mayor parte del territorio provincial, es decir, la penillanura, pertenece al bioclima supramediterráneo inferior, localizándose el mesomediterráneo superior en las sierras y piedemontes y el mesomediterráneo inferior en los Arribes del Duero. El observatorio meteorológico a mayor altitud (Presa de Béjar, 1275 m) nos hace suponer que todo este espacio serrano (macizo de Candelario) podría caracterizarse bioclimáticamente como supratemplado inferior húmedo superior, pues los datos meteorológicos que este registra así nos lo indican y, además, se trata de una montaña de mayor entidad que el resto del conjunto serrano de la provincia, aspecto este que hace que se incremente su efecto barrera y que, por lo tanto, aumenten las precipitaciones anuales y las temperaturas sean más rigurosas (Fernández, 2014).

\section{Objetivos y metodología}

\subsection{Objetivos}

El objetivo principal de este estudio se centra en analizar la correlación espacial entre los fitotopónimos, extraídos del MTN50, y la distribución de la vegetación potencial en la provincia de Salamanca (Mapa de Series de Vegetación de Rivas-Martínez, 2011). Con este propósito se han localizado los topónimos de carácter vegetal, referenciándolos en el mapa, y se ha verificado la correspondencia de su significado con respecto a las especies presentes en la provincia de Salamanca. Por ejemplo, el nombre vulgar más común en español de Alnus glutinosa es el aliso y los fitotopónimos relacionados con el aliso son "aliso", "aliseda", "alisera", pero en Salamanca según afirma Llorente (2003) existe también el topónimo de "oñoro" para identificar este árbol. En este caso, "Fuentes de Oñoro", que da nombre a una localidad fronteriza con Portugal, aparece citado en la hoja 525 del MTN50 que corresponde a Ciudad Rodrigo.

Además, se ha realizado una clasificación de los topónimos según diversos criterios que se especificarán más adelante, tales como la especie, el tipo biológico o la formación, después de haber verificado que los topónimos hacían referencia a una especie vegetal. En este último caso, se ha llegado a la conclusión de que en Salamanca el topónimo genérico de dehesa se emplea mayoritariamente para designar una formación arbórea de quercíneas, con mayor o menor densidad de árboles.

En último lugar, tras clasificar los fitotopónimos, se ha ensayado la correspondencia de las series de vegetación potencial con la localización de los topónimos de las especies más significativas, encontrando que existe un ajuste muy elevado entre aquellos que tienen un mayor número de citas. 


\subsection{Metodología}

En cuanto a la metodología, el proceso de trabajo implicó las siguientes fases:

a) Diseño de la base de datos primaria con diez campos fijos, de los cuales los seis primeros son de identificación y localización, mientras que el siete y el ocho son específicos del topónimo y el nueve y el diez son dos campos de clasificación general (Figura 2).

Figura 2. Estructura principal de la base de datos

\begin{tabular}{|c|c|c|c|c|c|}
\hline & & \multicolumn{2}{|c|}{ Clases del campo 9: Tipo de topónimo } & \multicolumn{2}{|c|}{ Clases del campo 10: Clasificación $1^{a}$} \\
\hline \multirow[b]{2}{*}{ CAMPOS } & \multirow[b]{2}{*}{ NOMBRE DEL CAMPO } & 9.a & Núcleo de población & 10.a & Agrotopónimo \\
\hline & & 9.b & Caserío/Diseminado & 10.b & Clima-Meteorología \\
\hline 1 & $N^{\circ}$ de la hoja del MTN & 9.c & Cota & 10.c & Fitotopónimo \\
\hline 2 & NOMBRE de la hoja del MTN & 9.d & Pago & 10.d & Zootopónimo \\
\hline 3 & Comarca Agraria & 9.e & Río, Arroyo y Fuente & 10.e & Geológico-Geomorfológico \\
\hline 4 & Coordenada X & 9.f & Embalse o charca & 10.f & GENÉRICO \\
\hline 5 & Coordenada Y & $9 . \mathrm{g}$ & Vía de comunicación & 10.g & DUDOSO \\
\hline 6 & HUSO UTM & 9.h & Minas y Canteras & & \\
\hline 7 & Artículo del nombre del topónimo & & & & 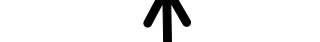 \\
\hline 8 & NOMBRE del topónimo & & & & \\
\hline 9 & Tipo de toponónimo & & & & \\
\hline 10 & Clasificación $1^{\text {a }}$ de significado & & & & \\
\hline
\end{tabular}

Fuente: elaboración propia

b) Vaciado de todos los topónimos de la provincia de Salamanca, excepto aquellos que tienen un origen reciente y están relacionados con actividades urbanas o de tipo industrial. Para ello se ha utilizado el Mapa Topográfico Nacional escala 1:50.000 (MTN50) publicado por el Servicio Geográfico del Ejército (Serie L), que ha sido la base cartográfica de la que se ha extraído la localización (coordenadas UTM) e identificación de los topónimos. Concretamente, el trabajo se ha realizado sobre las treinta y nueve hojas que cubren toda la provincia de Salamanca, de las que solamente doce son totalmente del territorio provincial, mientras que las veintiséis restantes lo comparten con las provincias adyacentes (Ávila, Cáceres, Valladolid y Zamora) y también con Portugal (Figura 3). Además, esta información se ha contrastado realizando comprobaciones aleatorias en ciertas hojas con otras ediciones del MTN del Instituto Geográfico Nacional (IGN) catalogadas entre los fondos documentales de la Biblioteca de la Universidad de Salamanca.

Conviene mencionar que en esta investigación no se distingue entre toponimia mayor y toponimia menor, y se valora de igual manera el topónimo vinculado con una gran sierra o un núcleo de población, como el que hace referencia a una alquería o a un pago, ya que todos ellos pueden transmitir información de carácter vegetal o paisajística muy valiosa. 
c) Georreferenciación de los topónimos utilizando la cuadrícula UTM en las hojas del MTN50. Para ello se han adscrito las coordenadas de cada uno de ellos en función de la posición de la primera letra del nombre, utilizando el ángulo suroccidental (inferior izquierdo) de la cuadrícula UTM en la que aparece (Figura 4). En esta primera etapa se han seleccionado todas las referencias toponímicas de la provincia de Salamanca para, en una segunda fase, trabajar únicamente con aquellos topónimos que sean de carácter vegetal.

El resultado de esta tarea se resume en un total de 9959 citas toponímicas para la provincia de Salamanca. En este trabajo entendemos por cita toponímica cada entrada de un registro en la base de datos, que puede hacer referencia a un único topónimo que se repite una o varias veces en la misma o en más hojas del MTN50. De este modo, si el mismo topónimo aparece tres veces en una de las hojas del MTN50 será incluido tres veces en la base de datos. Por ejemplo, el nombre de un río, que es un topónimo lineal, puede tener varias citas en una o en más hojas. Este es el caso del topónimo "Regato de la Fresneda", que aparece citado dos veces en la hoja 501 del MTN50 correspondiente a La Fuente de San Esteban.

Figura 3. Hojas del MTN50 en la provincia de Salamanca

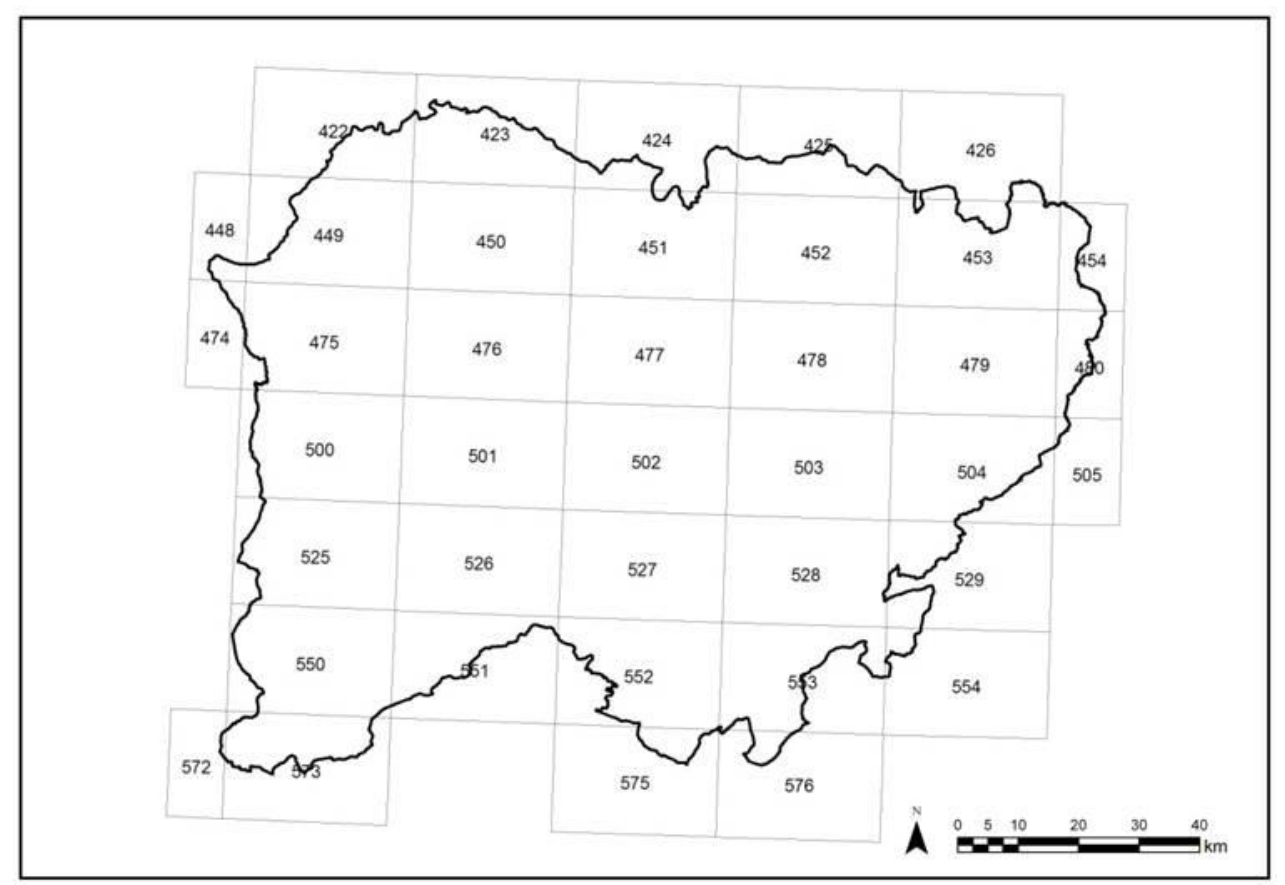

Fuente: elaborado a partir de la base de distribución de la cartografía del IGN 
Figura 4. Ejemplo de georreferenciación de topónimos utilizando la cuadrícula UTM

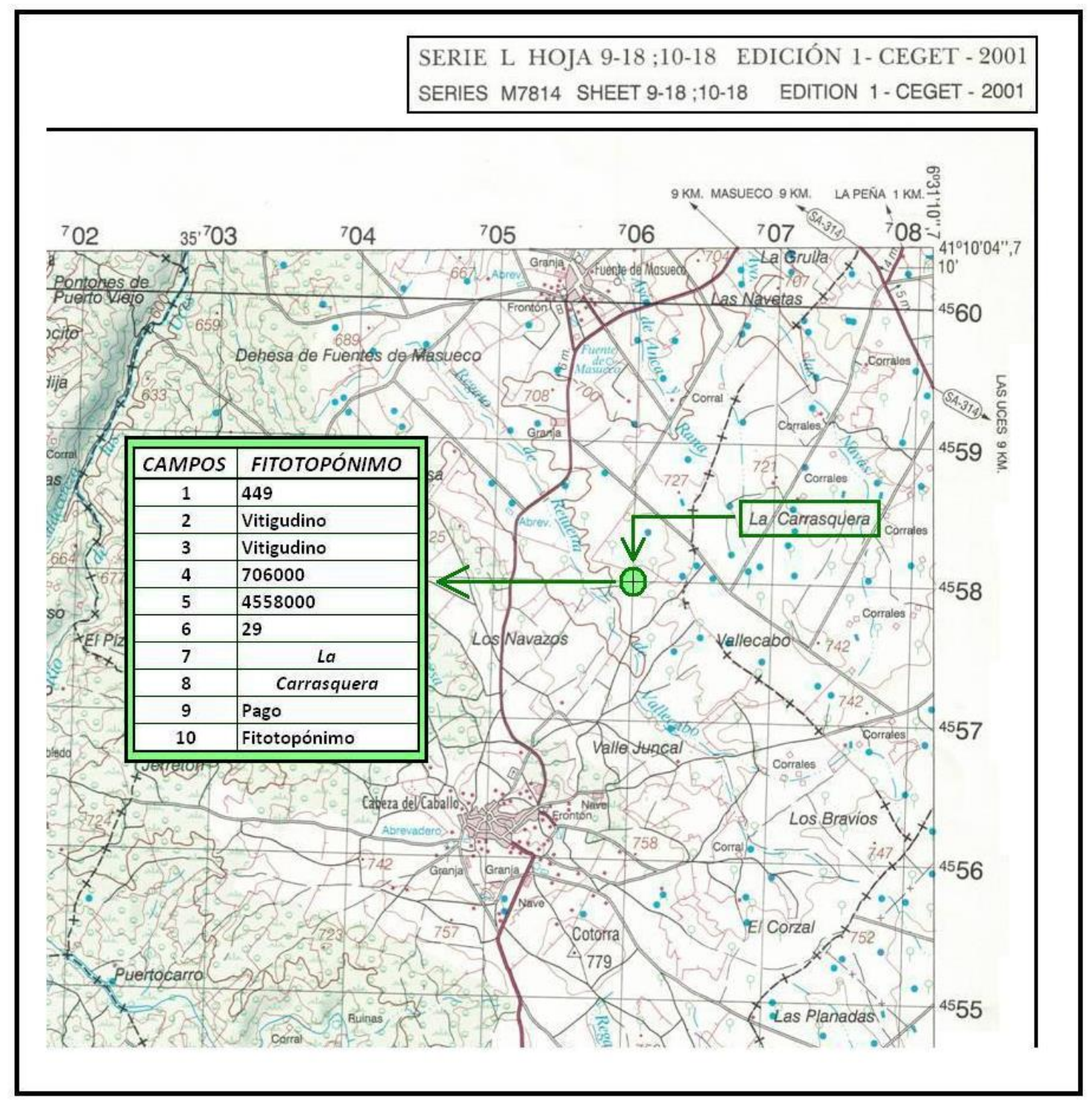

Fuente: Servicio Geográfico del Ejército Mapa General (Serie L)

Escala 1:50.000 Hoja 9-18 (449) Tamames. 2ª Edición 1993

d) Selección y clasificación de topónimos de carácter vegetal cuya identificación no ofrezca duda alguna. Para esta fase se ha empleado una obra fundamental como es la de Llorente y Llorente (2003) en la que se analiza la toponimia salmantina desde el punto de vista de la lingüística, desechando aquellos topónimos cuyo significado sea equívoco.

A la hora de clasificar una referencia toponímica como fitotopónimo se han incluido, tanto los topónimos transparentes ("Casa del acebo", caserío que aparece en el MTN50 n 552), como los que algunos autores denominan sinfitónimos (Benítez et al., 2009), es decir, topónimos que designan una colectividad vegetal o un conjunto vegetal ("La avellaneda", un pago en el MTN50 $n^{\circ}$ 553), pues estos también pueden facilitar la interpretación de la vegetación y del paisaje pretérito. Del mismo modo, se han analizado igualmente los denominados topónimos 
opacos, o sea, aquellos cuya interpretación resulta complicada y han de ser tratados desde la toponomástica (Molina, 2012), como el ya mencionado caso de "oñoro" para referirse al aliso.

e) Una vez identificados los fitotopónimos que con claridad hacen referencia a elementos vegetales, se han excluido dos cultivos leñosos muy comunes, la vid y el olivo, ya que esta investigación se centra en las formaciones vegetales de carácter natural y los dos están muy vinculados con producciones agrícolas. El resultado final obtenido ha sido de 1516 citas (el 15,2\% del total) a las que se le han añadido nuevos campos relacionados con la vegetación (Figura 5).

Figura 5. Estructura específica de la base de datos de fitotopónimos

\begin{tabular}{|c|l|}
\hline $\begin{array}{c}\text { Clases del campo 10.c } \\
\text { (Fitotopónimo) }\end{array}$ & \multicolumn{1}{|c|}{ EJEMPLOS } \\
\hline \hline Especies arbóreas & $\begin{array}{l}\text { Acebo, Álamo, Alcornoque, Aliso, Almendro, Avellano, Castaño, Cerezo, Ciruelo, Encina, } \\
\text { Espino/Majuelo, Fresno, Guindo, Higuera, Madroño, Manzano/Maillo, Morera, Mostajo, Nogal, } \\
\text { Olmo/Oñoro, Peral, Pino, Piorno, Quejigo, Roble, Sauce, Saúco y Tejo. }\end{array}$ \\
\hline Especies arbustivas & $\begin{array}{l}\text { Boj, Brezo, Carqueixa, Codeso, Endrino, Escoba, Genista, Hiedra, Jara, Piorno, Retama, Romero, } \\
\text { Ruda, Tojo, Tomillo, Torvisco y Zarza. }\end{array}$ \\
\hline Especies herbáceas & $\begin{array}{l}\text { Beleño, Berceo, Berro, Caña, Cardo, Gamón, Helecho, Heno, Hinojo, Junco, Ortiga, Poleo, } \\
\text { Romaza, Ruda y Trébol. }\end{array}$ \\
\hline Agrupaciones genéricas & Acuática (encharcados), DEHESA, MATA, MONTE y SOTO. \\
\hline $\begin{array}{c}\text { Agrupaciones de especies } \\
\text { arbóreas }\end{array}$ & $\begin{array}{l}\text { Barda/o (Bardal), Carba/Carbajo, Carrasco/a, Castañar, Chaparro/a, Chopera, Corchero/a, } \\
\text { Espinero/a, Mimbrera, Pinar, Poveda, Rebollar, Robledo/a y Sardón }\end{array}$ \\
\hline
\end{tabular}

Fuente: elaboración propia

f) Análisis estadístico y territorial de los fitotopónimos. En esta fase se analizaron sus principales cualidades y a continuación se estudió su caracterización en función de los tipos de especies vegetales y de las agrupaciones que estas forman. Además, dentro de las principales especies se analizaron, cuando eran representativas, las distintas denominaciones con las que aparecen en el área estudiada.

Con base en la metodología de trabajo definida por Marco (2004) para la provincia de Alicante, se realizó un estudio de la distribución territorial de la toponimia de carácter vegetal en la provincia de Salamanca. En primer lugar, y gracias a la georreferenciación de cada fitotopónimo, se procedió al análisis mediante un sistema de información geográfica (SIG), para identificar los lugares que cuentan con una mayor concentración de fitotopónimos, tratando de reconocer algunos factores que condicionan este hecho.

En segundo lugar, se realizó una representación cartográfica de los fitotopónimos clasificándolos por especies. Este análisis permitió ratificar si la localización de los mismos guarda relación con los dominios biogeográficos definidos actualmente, es decir, si, por ejemplo, el fitotopónimo roble y sus formaciones afines (robledales, melojares, bardales...) aparecen donde potencialmente debiera crecer Quercus pyrenaica. Se desecharon, por tanto, aquellos 
fitotopónimos que ni potencial, ni realmente pudieran hacer referencia a especies que prosperan en la provincia de Salamanca y, por lo tanto, no han de ser considerados como verdaderos fitotopónimos (ejemplos: "El Molino del Algarrobo", diseminado en el MTN50 n 551, no puede hacer referencia a Ceratonia siliqua sino que podría aludir a la planta forrajera, antiguamente muy cultivada en esta provincia o al dueño de la instalación que fuera conocido con ese apelativo; por su parte, el fitotopónimo "Alberca del Boj", pago en el MTN50 n 475, de ninguna de las maneras nos puede indicar la presencia de Buxus sempervirens, puesto que Salamanca no pertenece al área de distribución natural de esta planta).

g) Con las citas ya cartografiadas según su lugar de localización en el mapa base (MTN50), el análisis se centró en la correspondencia de estas con el Mapa de Series de Vegetación de RivasMartínez (2011). A la capa distribución de puntos de cada especie identificada, se superpuso la capa de vegetación potencial para evaluar su correspondencia. De esta manera, además de obtener una imagen nítida de la distribución actual de los fitotopónimos y de las series de vegetación, se podrá determinar, también, el número de citas cuya posición territorial no se corresponde con la de la vegetación a la que están haciendo referencia.

\section{Resultados}

Los resultados obtenidos se presentan en tres apartados sucesivos y relacionados: en primer lugar, se ha realizado un análisis de los topónimos, prestando especial atención a la toponimia de carácter vegetal; en segundo lugar, se ha analizado el tipo de vegetación a la que se refieren estos topónimos; y en tercer lugar se ha procedido a la cartografía y al estudio de la correspondencia de los fitotopónimos con la distribución potencial de la vegetación.

\subsection{Distribución estadística de los fitotopónimos}

De las 9959 citas toponímicas identificadas en la provincia de Salamanca, el 31,4\% hacen referencia al medio físico (el 11,5\% a la geología/geomorfología, el 4,2\% a la fauna, el 0,5\% al clima/meteorología), y concretamente, 1516 (15,2\% del total) aluden directa o indirectamente a la vegetación. De este modo, podríamos afirmar que la vegetación es un elemento destacado a la hora de denominar lugares dentro de la provincia de Salamanca. Este aspecto puede deberse a que, a excepción de su franja sur (territorio serrano), el conjunto provincial está constituido por formas del relieve relativamente llanas y uniformes que no son tan significativas como para denominar o caracterizar un lugar. Por tanto, en la isoaltitud imperante, destaca paisajísticamente de forma notable la vegetación hasta el punto de convertirla en un elemento identificador del territorio. El porcentaje restante $(68,4 \%)$ tiene un origen relacionado con actividades antrópicas.

La primera característica analizada ha sido el tipo de lugar al que hacen referencia los fitotopónimos. En este sentido, se han identificado los siguientes elementos: caserío/diseminado 
urbano, cota, embalse/charca, núcleo de población, pago, río/arroyo/fuente, vías de comunicación/minas/canteras.

De las 1516 citas un total de 974 (el 65\%) denominan espacios catalogados como pagos, es decir, lugares o parajes dentro del municipio con ciertas particularidades de usos agrarios tradicionales. Con mucha menos representatividad aparecen los grupos que se utilizan para denominar los cursos de agua (ríos o arroyos) y los caseríos o diseminados, con un $15 \%$ y un $10 \%$ respectivamente (Figura 6 ).

Conviene destacar que los nombres de los núcleos de población, lo que se entiende como toponimia mayor, solo representan el $4 \%$ de los fitotopónimos (60 citas), siendo el resto toponimia menor. Para comprender el destacado protagonismo de esta última, conviene no pasar por alto el carácter agro-silvo-pastoril de la mayor parte del territorio provincial: áreas boscosas ahuecadas donde la vegetación, especialmente la arbórea, resulta uno de los principales recursos, tanto para el alimento del ganado como para otros usos (leña, carboneo...). Por lo tanto, la importancia que esta puede tener en estos territorios es notable, hasta el punto de denominarlos.

Figura 6. Fitotopónimos por lugares de referencia

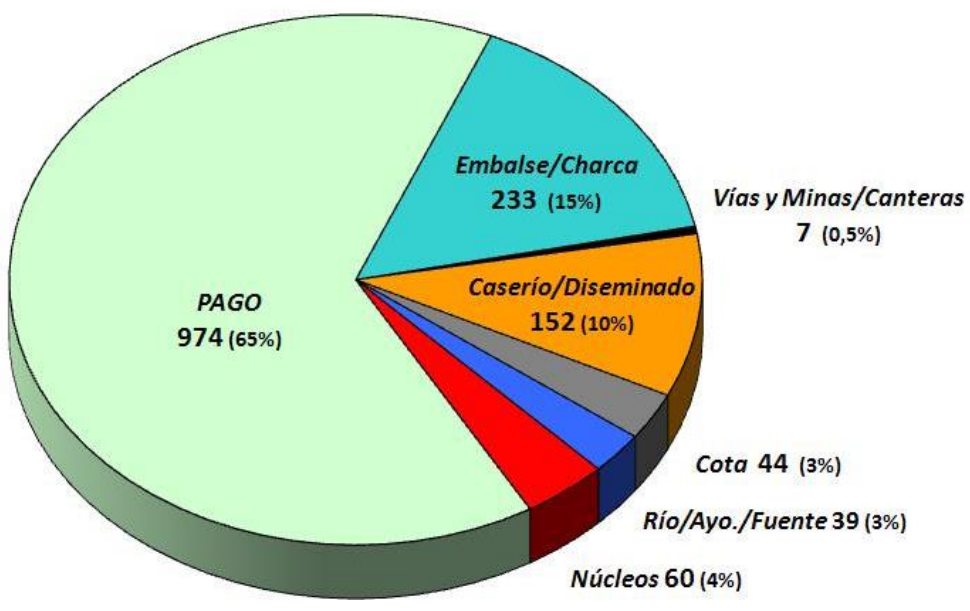

Fuente: elaboración propia

\subsection{Fitotopónimos según su clasificación morfológica}

Al proceder con el análisis de los fitotopónimos según su clasificación morfológica de la ciencia botánica, los grupos identificados se corresponden con los principales tipos biológicos: árboles, arbustos, acuáticas, hierbas/helechos, añadiendo una quinta figura que tiene que ver con aspectos genéricos (agrupaciones vegetales que podrían tener varios significados y que no se centran en una especie concreta). En este sentido, el grupo relativo a los árboles (macro y mesofanerófitos) es el más destacado con 748 citas fitoponímicas, en torno al 49 \% del total, haciendo alusión a alguna especie que podría integrarse en este grupo (Figura 7). 


\section{Figura 7. Grandes grupos de fitotopónimos}

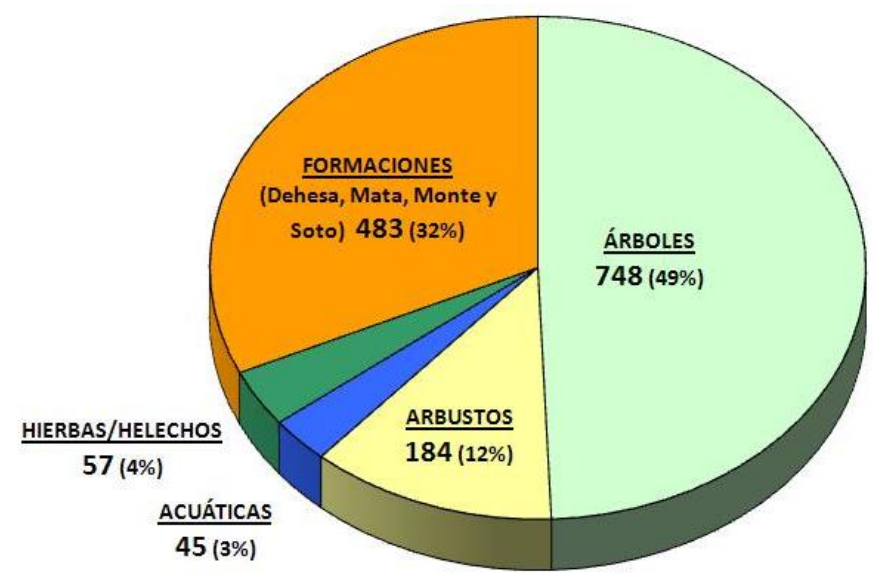

Fuente: elaboración propia

El grupo de los arbustos (micro y nanofanerófitos; caméfitos) cuenta con un total de 184 citas (12\%), siendo escasas las referencias a las agrupaciones y formaciones de matorrales, exceptuando los jarales, los tomillares y los retamales (escobales). Por el contrario, el grupo de fitotopónimos relativo a las plantas acuáticas (3 \% del total) raramente contiene nombres de especie, si exceptuamos berro, siendo la mayoría relativos a las agrupaciones relacionadas con territorios cuyo nivel freático aflora en superficie, como, por ejemplo, juncales, tremedales, trampales, etc. Finalmente, el número de citas restantes, 483 citas que suponen el 32\%, integran las formaciones de tipo "genérico" (dehesa, soto, monte y mata).

La escasa representación de las plantas de pequeño tamaño debe estar relacionada con la lógica dificultad de las mismas para caracterizar un territorio, mientras que las de gran porte, más visibles y destacadas, otorgarían una personalidad individualizada y singularizada a determinados espacios. Así sucede con las grandes agrupaciones paisajísticas, cuya aparición evidencia un reconocimiento del aspecto del terrazgo por parte de los habitantes del medio y que tienen implícito un uso antiguo de carácter pecuario y forestal. En esta última categoría están incluidas las referencias a las dehesas, a las matas, a los montes y a los sotos. Conviene destacar igualmente que el topónimo "dehesa" adquiere una relevancia especial: han sido identificados 230 fitotopónimos que incluyen esta denominación en sus distintas variantes, lo que supone aproximadamente la mitad de las referencias del grupo diferenciado como "formaciones". Concretamente, la "dehesa" en la comarca salmantina de El Campo Charro suele referirse a la explotación de características agro-silvo-pastoriles (definición clásica y extensa de este elemento agrario), en cambio, en las sierras del sur de la provincia (contexto montañoso), este mismo topónimo, habitualmente, se refiere a las "dehesas boyales", espacios que tradicionalmente eran de uso comunal para el pasto y resguardo del ganado vacuno, que suele coincidir, en su mayor parte, con los Montes de Utilidad Pública. Según el estudio de Morales y Morales (2000) la 
extensión de las dehesas en Salamanca sería de aproximadamente 7820 km², lo que supone más de la mitad de la superficie total de la provincia, siendo muy destacada su presencia en el sector occidental de la misma. Por tanto, parece razonable que este topónimo aparezca con mucha frecuencia en la cartografía, pues esos pagos habrían sido designados así en función de la propia explotación.

a) Árboles y formaciones boscosas

En la categoría identificada con el nombre de "árboles" (748 citas fitotoponímicas) las especies más representadas son la encina y el roble melojo/rebollo (Figura 8). En el caso de la encina (183 referencias) aparece con cinco versiones diferentes: encina/encino/encinares (50 citas), carrasco/carrasca/carrascales (115 citas), carba/carbajo/carbajosa y carbajales (10 citas), chaparro/chaparra/chaparrales (3 citas) y sardón/sardonales (5 citas). Respecto a Quercus pyrenaica, cuenta con 129 citas que en Salamanca aparecen con la denominación de roble/robledo/robleda (48 citas), barda/bardo/bardal (62 citas) y rebollo/rebollar (19 citas). Ambas especies son, a la postre, las que mayor superficie ocuparían si atendemos tanto a la distribución potencial de la vegetación, como a la distribución real de la misma en la provincia de Salamanca, y por ello, no resulta extraño que sean estas dos las especies mayoritarias.

Figura 8. Topónimos referidos a árboles

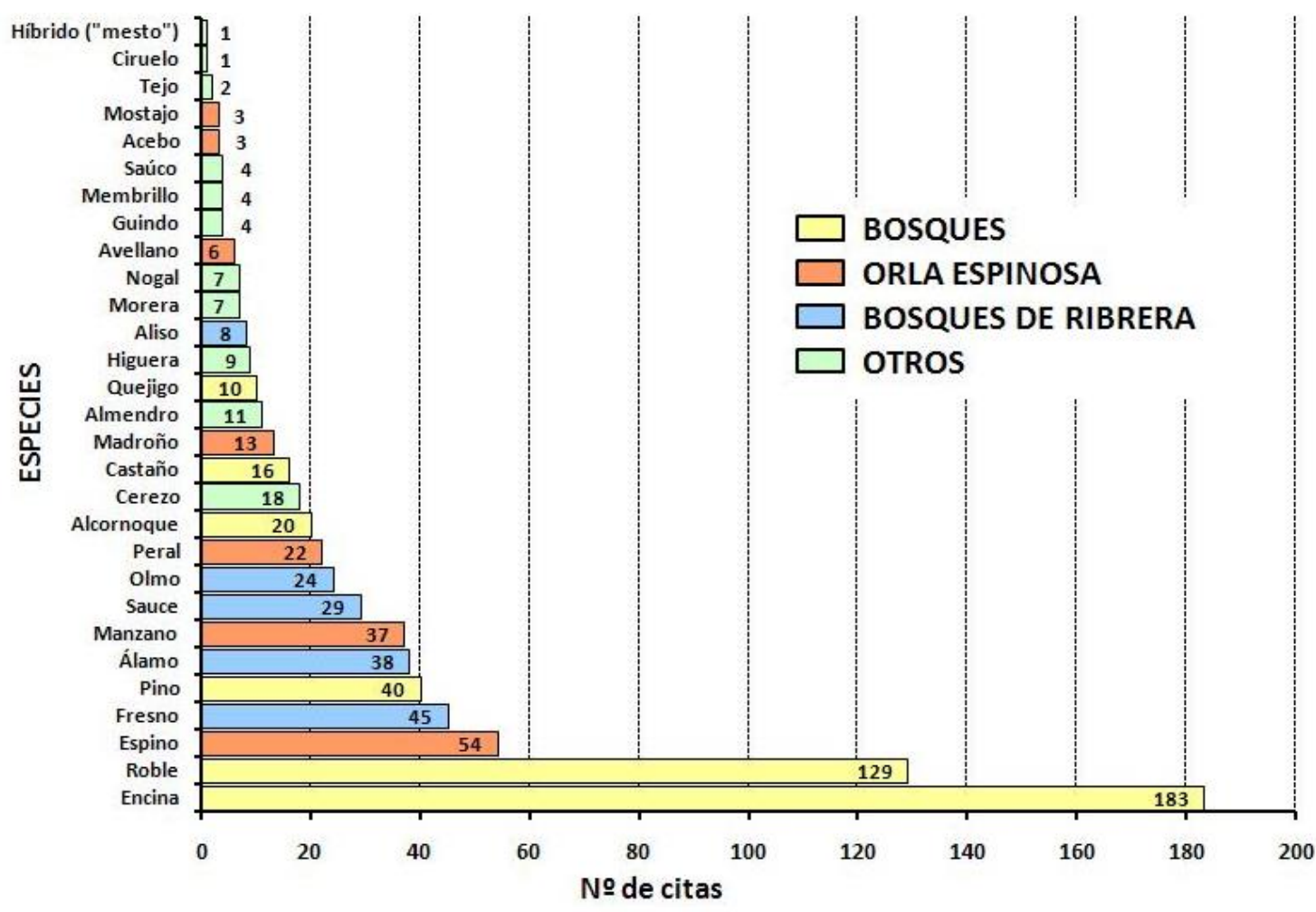

Fuente: elaboración propia 
Hay otras dos quercíneas que cuentan con representación en la toponimia salmantina: el alcornoque (Quercus suber) con 20 citas (ejemplo: "Arroyo del Alcornoque", un curso de agua en el MTN50 n 526) y el quejigo (Quercus faginea) con 10 (ejemplo: "Navas del Quejigal", un núcleo de población en el MTN50 n 477). Es llamativa también la aparición de un único topónimo del mesto, híbrido entre dos especies de quercíneas ("Los Mestos", pago en la hoja del MTN50 n 477).

Las distintas especies de pinos que crecen en la provincia de Salamanca ( $P$. sylvestris, $P$. pinaster, $P$. pinea), aunque se consideran como formaciones boscosas, no entran dentro del ámbito de la vegetación potencial puesto que son, en su mayoría, repoblaciones, especialmente las consolidadas en las sierras del sur de Salamanca, ocupando el medio propio del rebollar. En el caso del castaño, también especie alóctona y cultivada desde época romana, sobre todo en los municipios serranos (por ejemplo, Miranda del Castañar), ha tenido un notable aprovechamiento maderero (vigas de construcción y cestería). En resumen, el total de citas referidas a todos estos fitotopónimos que hacen referencia a formaciones boscosas alcanzan las 398, lo que supone más de la mitad de los topónimos vinculados con árboles (53,2\%).

El siguiente grupo con un 19,2\% es el de los bosques de ribera, en el que destacan los fresnos y álamos. Se ha localizado la presencia de fresno (Fraxinus angustifolia) con 45 citas, álamo-chopo (Populus sp.) con 38, sauce (Salix sp.) con 29 y aliso (Alnus glutinosa) con 8 citas. Ya se mencionó que el aliso cuenta con una denominación infrecuente en la provincia de Salamanca donde aparece como oñoro, al igual que ocurre con el olmo (Ulmus minor) cuyo topónimo más frecuente en Salamanca es el de negrillo ("Fuente de los Negrillos", fuente en el MTN50 n 550).

Con un número de citas similar se encuentran los árboles de pequeño porte, que forman parte de la orla espinosa de los principales bosques, entre los que los fitotopónimos relativos a Crataegus monogyna (espinera, majuelo o espinar) tienen un protagonismo principal ${ }^{1}$. Un caso especial para esta provincia es el del manzano silvestre (Malus sylvestris), que también recibe el nombre de maílo (ejemplo: "Río Maíllo", un curso de agua en el MTN50 n 527). Como se verá más adelante, parece que se puede vincular al manzano silvestre con la orla espinosa de los robledales y al peral con la de los encinares, aunque evidentemente ambas rosáceas pueden crecer en los dos tipos de bosques. Por ejemplo, "Peralejos de Solís", un núcleo de población en el MTN50 n 502, estaría haciendo referencia a una zona en la que aparecen perales silvestres junto a un curso de agua (Arroyo Varazas), dentro del gran dominio del encinar en el centro y el este de la provincia.

1Conviene tomar el término majuelo con cierta precaución porque Sanz y González (2006) señalan que en la cercana provincia de Segovia, se denomina majuelo a un terreno plantado de viñas, por lo que podría suceder lo mismo en la provincia de Salamanca. 
Por último, aparecen citas de otros árboles que en su mayoría son frutales y están vinculados a los aprovechamientos antrópicos (cerezo, almendro, higuera...). En estos casos su localización no obedece a un patrón de distribución natural dentro de las series de vegetación potencial de la provincia de Salamanca. Por ejemplo, los topónimos "Cerezal de Peñahorcada", "Cerezal" y "Arroyo del Cerezo", localizados respectivamente en las comarcas agrarias de Vitigudino (Los Arribes del Duero), Salamanca (La Armuña) y Béjar (Sierra de Béjar), demuestran que la distribución de esta especie es aleatoria.

\section{b) Arbustos (matorrales), herbáceas y acuáticas}

Para empezar el comentario respecto a los topónimos referidos a arbustos y matorrales, hay que advertir que el fitotopónimo con más citas (61) es el de zarza y sus derivados (zarcera, zarcerón, etc.) y tiene un significado muy genérico porque engloba desde las zarzas propiamente dichas (Rubus sp.), las rosas (Rosa sp.) e incluso los espinos mencionados en el epígrafe anterior (C. monogyna). Es decir, zarceras y zarzales tienen una equivalencia directa con espineras y espinares, todos ellos dentro de la orla espinosa de la mayoría de los bosques.

En segundo lugar, si nos circunscribimos a los matorrales propiamente dichos, tenemos que empezar citando a las jaras (Cistus sp.) con 33 referencias, los brezos (Erica sp.) con 20 y las escobas (Cytisus sp.) y retamas (Retama sp.) con 18 y 4, respectivamente. Todas ellas hacen referencia a formaciones secundarias en las series de sucesión vegetal de los principales bosques ya comentados, encinares y robledales. Después de estas, con un número de citas menor, aparecen tomillo (16 citas), piorno (10) y gamón (8), que podemos considerar como formaciones subarbustivas asociadas a suelos muy degradados (taludes, berrocales, etc.), siendo la fase posterior del pastizal vivaz y/o del suelo desnudo.

En cuanto a los topónimos que pudieran adscribirse a un significado referido a herbáceas, plantas acuáticas, helechos y plantas nitrófilas, se han identificado un total de 102 citas. En este grupo destacan los vinculados con ambientes edáficos de encharcamiento, haciendo referencia a las formaciones más que a las especies concretas: por ejemplo, juncal (27), tremedal, trampal y bodón (16) , caña (10), etc.

\subsection{Análisis territorial}

El análisis de la distribución territorial de los fitotopónimos identificados se ha representado cartográficamente atendiendo a la densidad de los mismos utilizando el estadístico denominado distribución Kernel (Figura 9). De esta manera, aunque la distribución de estos es relativamente homogénea por toda la provincia, aplicando este estadístico se ha obtenido un valor de densidad basado en la vecindad entre fitotopónimos que hemos clasificado en tres categorías cualitativas: alta, media y baja. Las comarcas agrarias que presentan una mayor concentración de fitotopónimos son aquellas que tradicionalmente han contado con una vocación agro-silvo-pastoril, como ocurre 
en el noroeste de la comarca agraria de Vitigudino con Los Arribes del Duero, que es el territorio que cuenta con mayor riqueza fitotopónimica, ya que reúne el 23,4\% de todas las citas de carácter vegetal de la provincia. Este hecho, tal vez se podría relacionar con la variedad de usos del suelo tradicionales que ha perdurado hasta la actualidad.

Figura 9. Concentración de fitotopónimos según la distribución Kernel

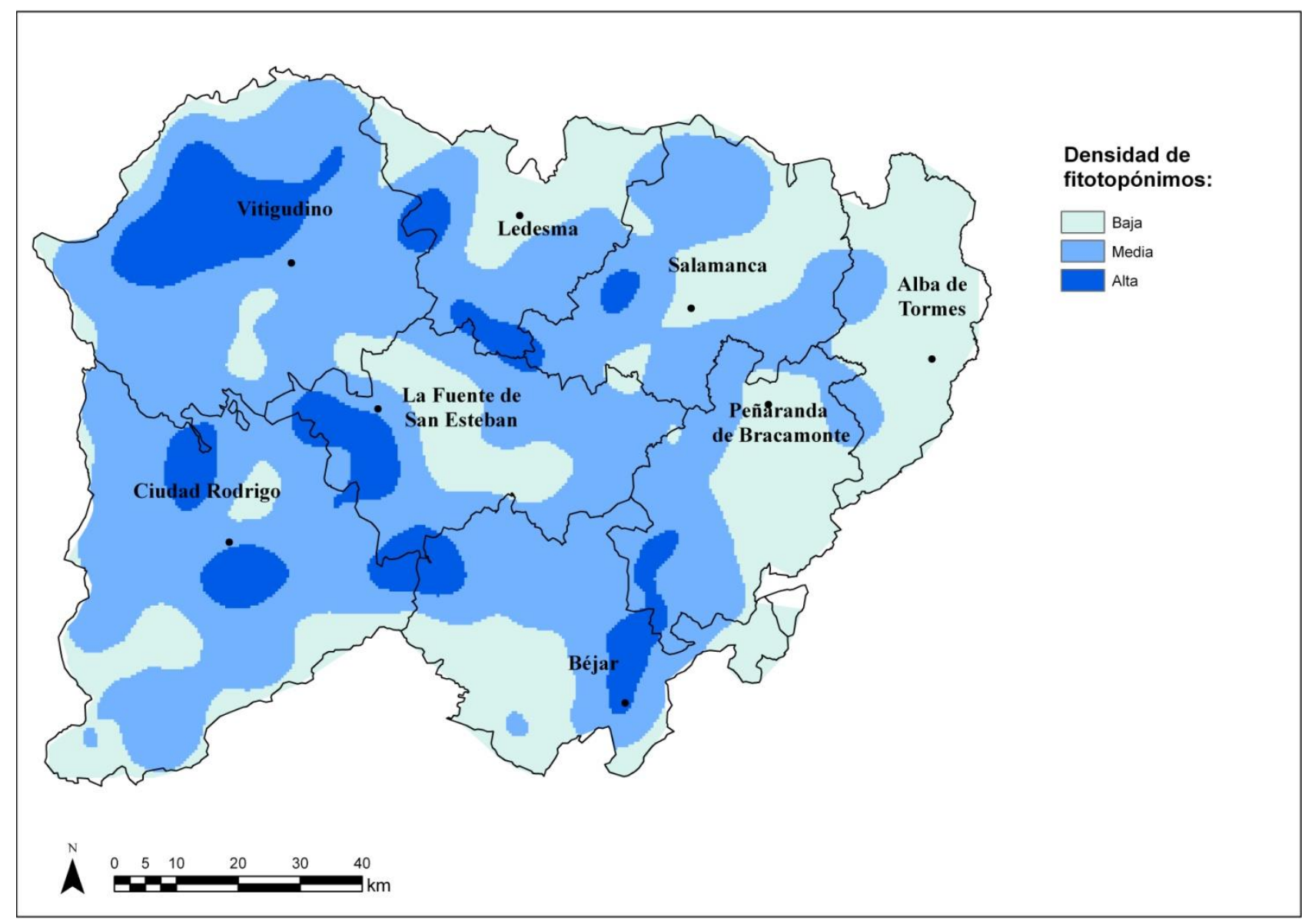

Fuente: elaboración propia

Otra de las áreas que cuenta con una gran densidad de citas fitotoponímicas es la franja de terreno que se extiende por la zona de piedemonte o el contacto entre el conjunto serrano y la submeseta, desde Béjar a Ciudad Rodrigo, y se amplía hasta la Fuente de San Esteban, lo que coincide con el dominio del espacio adehesado cuyo uso predominante es la ganadería extensiva. En sentido contrario aparecen algunas comarcas agrarias monofuncionales, como son el Campo de Peñaranda, la comarca agraria de Salamanca y gran parte de la de Alba de Tormes, donde predominan las actividades vinculadas con el sector agrícola, hoy en día notablemente tecnificado. Por tanto, parece identificarse una relación entre mayor densidad de topónimos de carácter vegetal y variedad de usos del terrazgo, mientras que las zonas agrícolas contarían con menos referencias de este tipo. 
A continuación, se ha llevado a cabo un análisis de la distribución de los fitotopónimos, superponiendo su localización sobre el mapa de series de vegetación de Rivas-Martínez (2011). Partiendo del hecho de que la provincia de Salamanca tiene un $95 \%$ de su territorio adscrito a las formaciones potenciales de encinares y robledales, no es extraño que sean los fitotopónimos relativos a la encina y el roble los que tengan un mayor número de citas.

\section{Figura 10. Distribución de las citas toponímicas de roble y de encina y su correspondencia con los dominios potenciales de vegetación}

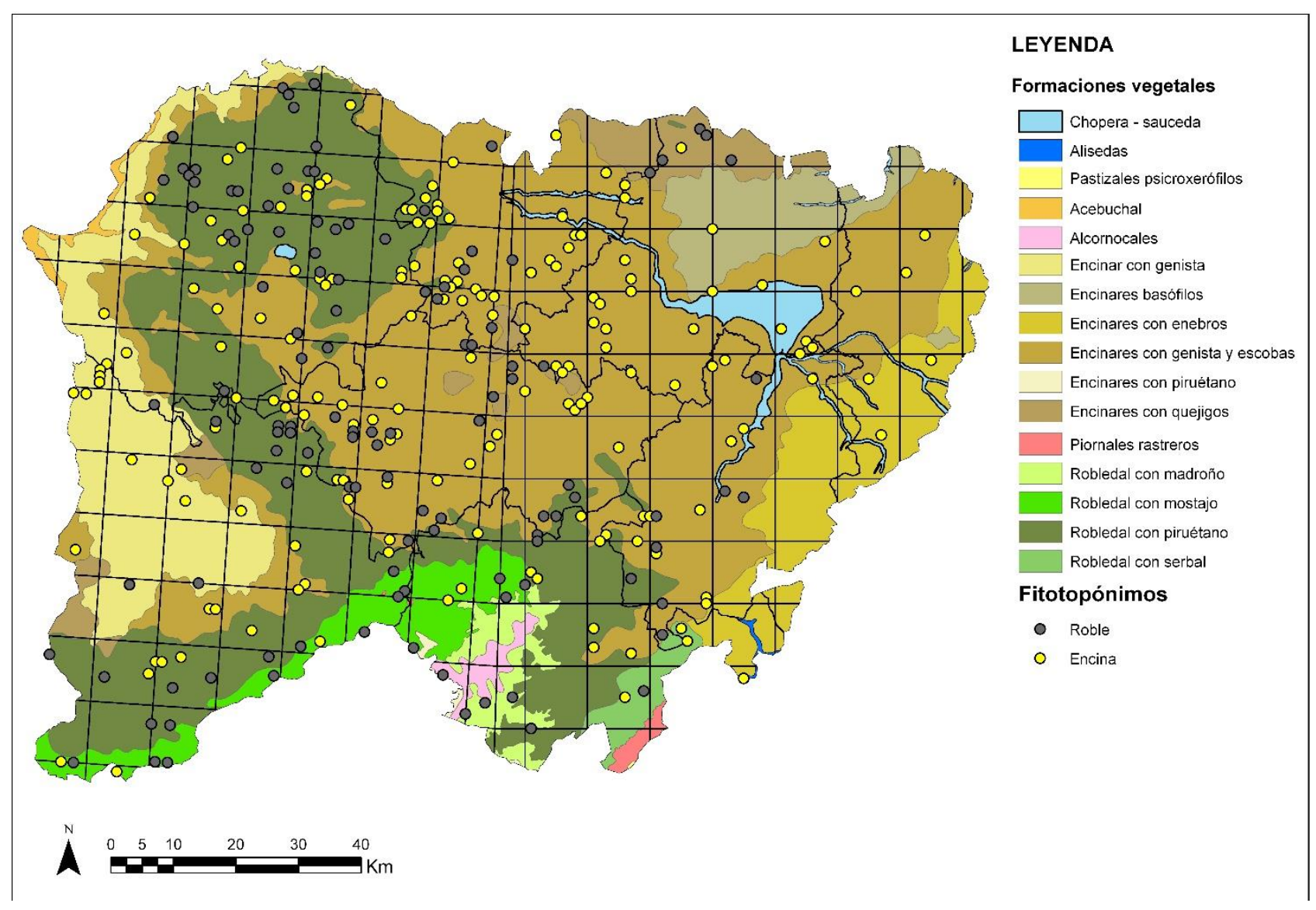

Fuente: elaboración propia a partir de Rivas-Martínez (2011)

Si observamos la Figura 10, se advierte una correspondencia bastante ajustada entre la presencia de topónimos relativos a la encina y al roble con el área de distribución potencial de los encinares y robledales. Además, la presencia de fitotopónimos de encina en el área que potencialmente se corresponde con el robledal, y viceversa, no supone una gran distorsión en este ajuste desde el punto de vista ecológico. Es decir, no es infrecuente encontrar bosques mixtos de roble y encina, dado que se trata de dos especies de árboles con exigencias bioclimáticas muy amplias y semejantes (Maldonado et al., 2002; López, 2004) y de una provincia cuyo territorio mayoritariamente es plano. Lo más destacable del área de distribución potencial del roble no es su localización zonal al sur de la provincia, coincidiendo con las sierras, si no la franja que une esta 
última con el norte de la provincia a través de las comarcas agrarias de Ciudad Rodrigo y Vitigudino. Este territorio coincide con el leve resalte topográfico que introduce el interfluvio entre los ríos Tormes y Águeda donde se eleva ligeramente el valor anual de precipitación. Esta franja azonal sería, por tanto, un área de transición entre las dos áreas de distribución potencial.

Desde el punto de vista cuantitativo, de las 183 citas toponímicas referidas a la encina, el 68 \% se localizan dentro del territorio de distribución potencial de la misma. En el caso del roble, la correspondencia es aún mayor: el 74,4\% de ellas se encuentran dentro de su área. Se ha de considerar que la mayor parte de las citas que se ubican fuera del contexto del roble estarían remarcando esa área de transición antes mencionada, aspecto este que ayudaría a matizar la presencia de estos topónimos fuera del lugar que se consideraría normal para su distribución potencial.

Es interesante señalar que de los tres tipos de fitotopónimos que aparecen referidos al roble melojo en la provincia de Salamanca (roble, barda, rebollo), este último es el que menos veces aparece mencionado (15\% de las citas), y sin embargo, es el que designa con mayor fiabilidad a Quercus pyrenaica ya que las 19 referencias aparecen dentro de las series de vegetación del robledal o muy próximos a ellas, mientras que las referencias a barda o a roble aparecen sensiblemente más alejadas de las áreas potenciales donde podría crecer esta especie. Curiosamente, una de las denominaciones tradicionales en Salamanca para la parte más occidental de la sierra de Gata es la de "El Rebollar", Ilamado "Campo de Robledo" durante el siglo XVIII y perteneciente al antiguo Partido Judicial de Ciudad Rodrigo (Mateos, 1966). Por tanto, parece que no existe duda de que por "rebollo" debe entenderse Quercus pyrenaica (Llorente, 1995).

Por tanto, parece evidente que la elevada correspondencia entre la distribución de estos dos topónimos indica que, en el caso de la provincia de Salamanca, los grandes árboles son utilizados para denominar espacios en los que aparecen como especie mayoritaria o destacada, siendo pocas las situaciones en las denominarían un espacio en el que no son la especie predominante.

En el caso de los arbustos que son propios del cortejo florístico de los rebollares, conviene mencionar al madroño, al mostajo y al manzano silvestre (localmente llamado maíllo) porque, sobre todo el primero de estos tres pequeños árboles, contribuye a la identificación de una de las asociaciones vegetales del robledal (Arbuto unedonis-Quercetum pyrenaicae). El primero, cuenta con 13 citas, de las que el 85\% están dentro de la unidad "robledal con madroño", estando las restantes a menos de 15 kilómetros del límite de la distribución potencial. Del segundo aparecen tres referencias en el límite suroccidental de la provincia, localizadas en la sierra de Gata dentro de la serie "robledal con mostajo" (Figura 11), correspondiéndose así con el área de presencia potencial de esta especie. En cuanto al maíllo, la distribución de los fitotopónimos se intensifica en el sector occidental de la provincia, especialmente en torno al núcleo de El Maíllo y a la comarca 
agraria de Ciudad Rodrigo. Por su parte, el peral o piruétano (Pyrus sp.) que aparece como acompañante de la encina en la denominación de la asociación vegetal (Pyro bourgeanaeQuercetum rotundifoliae), tiene una distribución muy repartida por el territorio y se corresponde con los espacios adehesados de la provincia.

Figura 11. Fitotopónimos relativos al madroño, al mostajo, al manzano y al peral y su correspondencia con los dominios potenciales de las series de vegetación del encinar y robledal

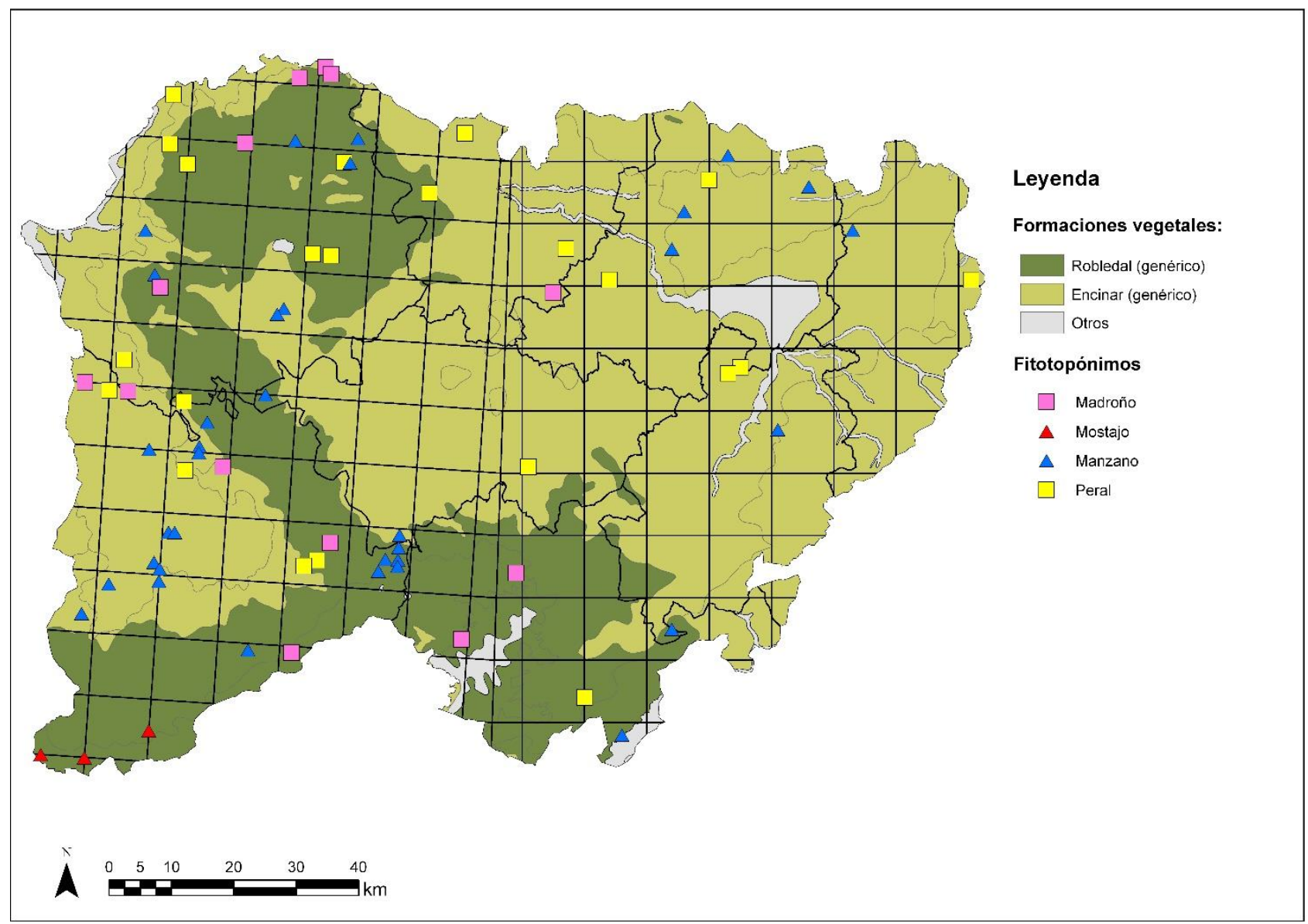

Fuente: elaboración propia a partir de Rivas-Martínez (2011) y MTN50 del Servicio cartográfico del Ejército

Si adscribimos las retamas/retamares (Retama sphaerocarpa) y las escobas/piornales (Cytisus sp.) como matorrales de las series de los encinares y robledales, se observa que, en el primer caso, todas las citas se encuentran situadas dentro del área de distribución de la encina, mientras que en el caso de las escobas, el porcentaje de correspondencia es del 71 \% (Figura 12). 
Figura 12. Fitotopónimos relativos al brezo, la jara, la retama y la escoba y su correspondencia con los dominios potenciales de las series de vegetación del encinar y robledal

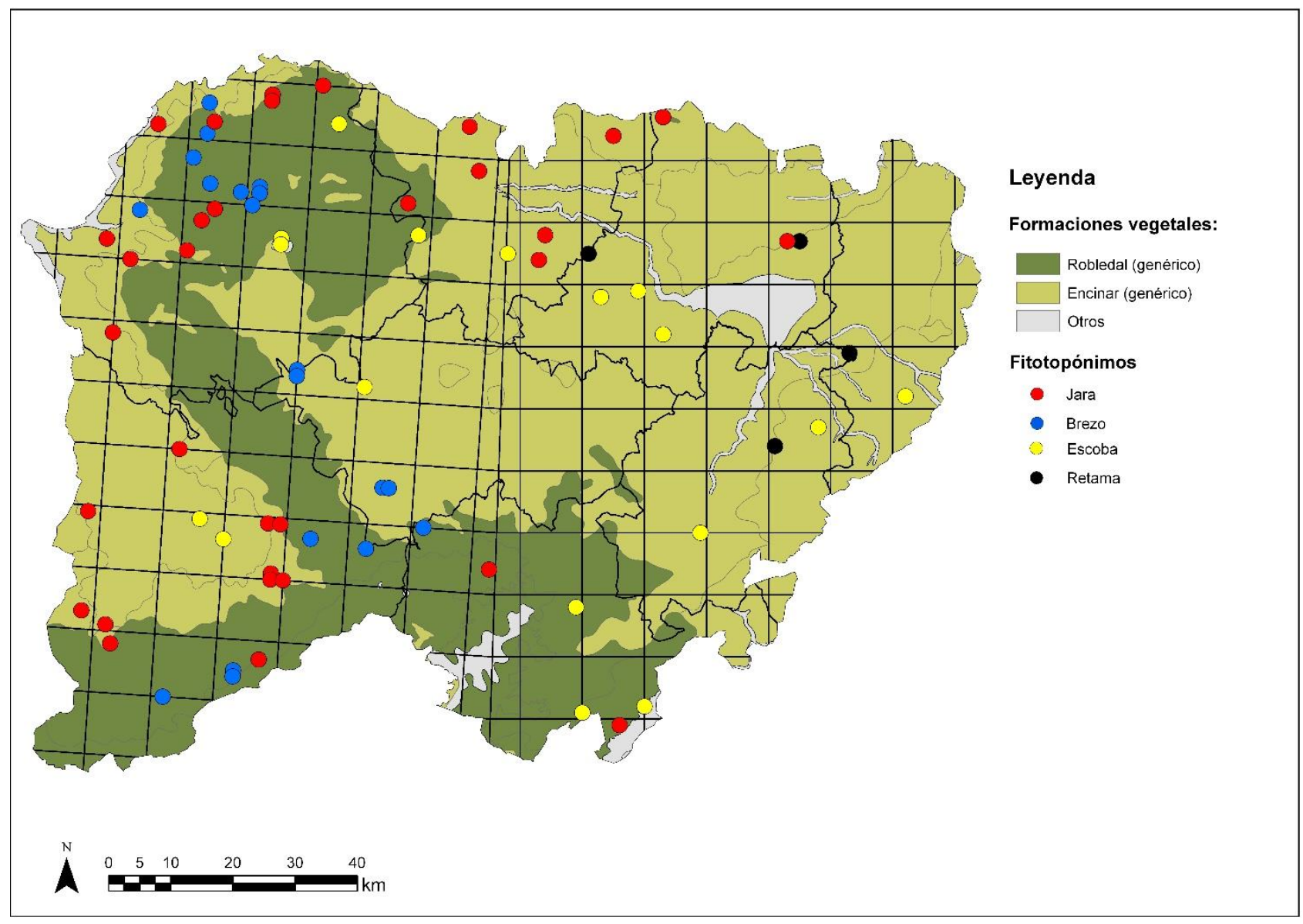

Fuente: elaboración propia a partir de Rivas-Martínez (2011)

y MTN50 del Servicio cartográfico del Ejército

Los dos últimos arbustos y sus correspondientes matorrales de los que se puede extraer una correlación con la vegetación potencial son el brezo y la jara. En la Figura 12 se advierte, en primer lugar, que los fitotopónimos relativos a estos matorrales dominan en el occidente de la provincia, es decir, en el área más pecuaria, mientras que no existen apenas citas en las comarcas agrarias de Salamanca, Alba de Tormes y Peñaranda de Bracamonte, que tradicionalmente son las más agrícolas. En segundo lugar, se observa que tanto el brezo y la jara coinciden con el área de distribución de rebollares y encinares, respectivamente. Hay que mencionar que el brezo, en la Sierra de Gata, se explotó para elaborar carbón vegetal hasta principios del siglo XX:

Y viven los del Rebollar con los pocos cultivos de sus tierras centeneras, con los ganados, especialmente las cabras, que en sus montes se crían, y con el carbón de brezo que hacen y que exportan a Extremadura y a Salamanca (Pérez, 1922, p. 120). 
En cuanto a la distribución de las especies arbóreas de ribera, se han identificado un total de 120 citas en la provincia de Salamanca que se refieren al fresno, álamo-chopo, sauce y aliso. En estos casos, la correspondencia no se hará con el mapa de vegetación potencial de Rivas-Martínez (2011), si no con la red hidrográfica debido a su carácter edafohigrófilo y a que tiene una representación cartográfica lineal (Figura 13). Es evidente que la vegetación de ribera se asocia con zonas de elevada humedad edáfica y, por tanto, no se puede hablar exclusivamente de una correlación entre las series de vegetación "aliseda" o "chopera-sauceda" y los fitotopónimos anteriormente mencionados.

Figura 13. Fitotopónimos relativos a los árboles de ribera

y su correspondencia con la red hidrográfica

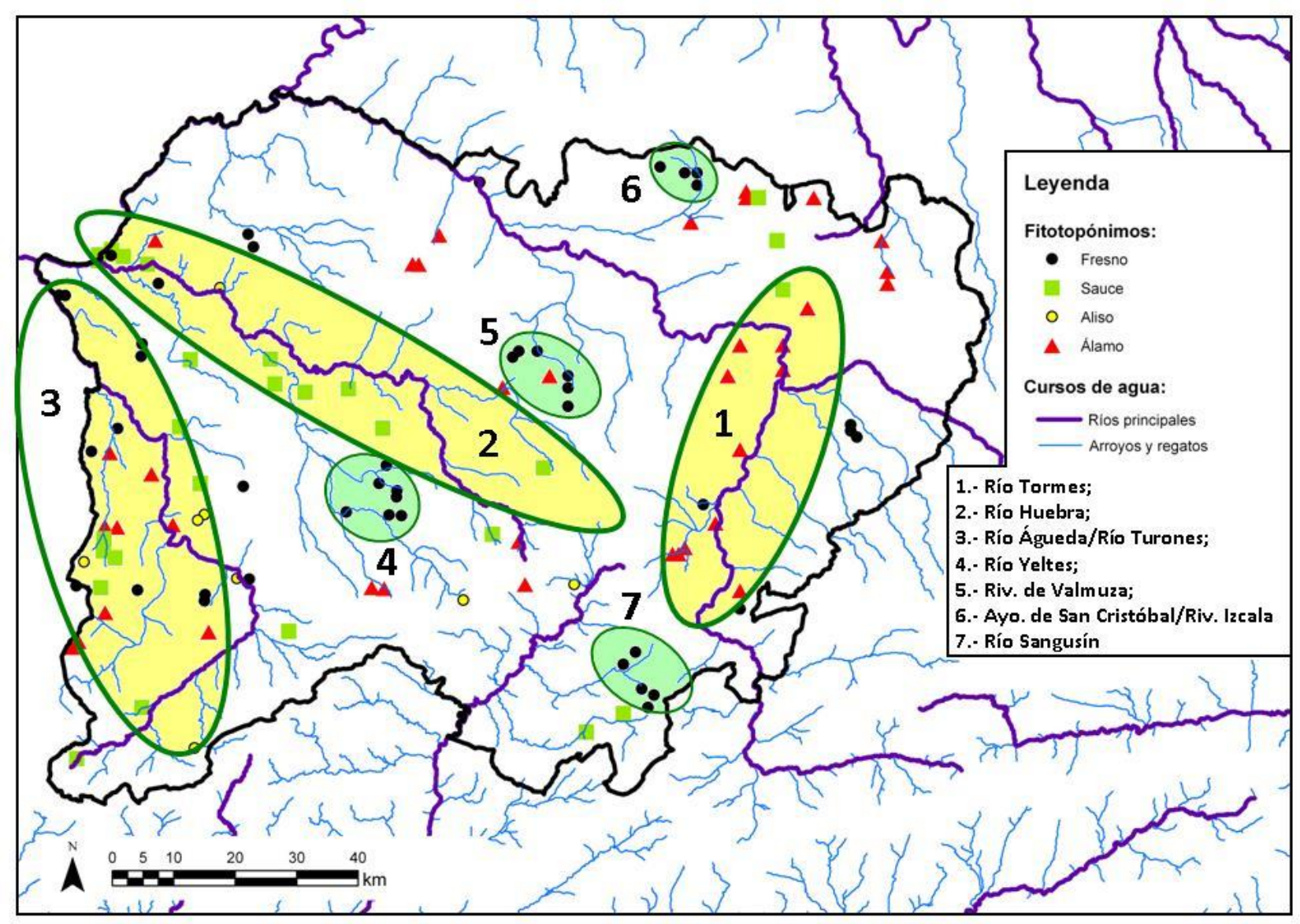

Fuente: elaboración propia a partir del MTN50 del Servicio cartográfico del Ejército

Los álamos-chopos (básicamente choperas de repoblación) y los sauces, así como sus respectivos fitotopónimos son los más abundantes del grupo de la vegetación de ribera, y están asociados a todos los cauces, especialmente a los cursos de agua permanentes: los álamos al curso medio del Tormes ( $n^{\circ} 1$ de la Figura 13) y los sauces al del Huebra ( $\left.n^{\circ} 2\right)$. En ambos casos, así como en el valle del río Águeda ( $n^{\circ} 3$ ), donde también se han localizado fitotopónimos relativos a estas dos especies, además de adscribirse a cursos de agua permanente, hay que vincularlos a que en estos 
tres valles existen terrazas aluviales bien desarrolladas, con suelos detríticos muy sueltos, lo que favorece el crecimiento radicular de estos árboles en busca del nivel freático. En el caso del valle del Tormes destaca que los álamos solo aparezcan en su tramo medio ( $\left.n^{\circ} 1\right)$, donde hay terrazas, mientras que en el curso alto y bajo desaparecen las referencias toponímicas ya que en ambos sectores el río circula sobre el zócalo.

En el caso de los fitotopónimos relativos al álamo, que se localizan al norte de las comarcas agrarias de Salamanca y Alba de Tormes (lo que se corresponde con la comarca tradicional de La Armuña), suponemos que no hacen referencia a Populus nigra, sino a Populus alba, cuestión que parece lógica pues es lo que se observa en todos los cauces estacionales del centro de la cuenca del Duero, donde coexisten suelos sueltos aluviales y valores térmicos estivales más elevados.

Por último, los fresnos y sus fitotopónimos se concentran en cuatro sectores $\left(n^{\circ} 4,5,6\right.$ y 7$)$ que tienen en común varias características: se trata de valles con cursos de agua estacionales donde el nivel freático es elevado y los suelos son aluviales, pero no se trata de terrazas propiamente dichas, es decir, con suelos profundos y muy desarrollados. Además, estos espacios se corresponden con áreas de vocación pecuaria, en las que el fresno, que lógicamente ocupa las vaguadas, jugaba un papel relevante como complemento en la alimentación del ganado bovino extensivo con el aprovechamiento del ramón durante el periodo estival mediante la poda a "cabeza de gato".

\section{Conclusiones y discusión}

En esta investigación se ha estudiado la fitotoponimia en una de las provincias españolas en las que el paisaje rural ha sido menos transformado y que, a su vez, aún permanece en buen estado de explotación. Es decir, los cambios tecnológicos relativos a nuevos cultivos o las nuevas técnicas de aprovechamiento experimentadas en el medio rural español, en el caso de la provincia de Salamanca no han alterado la vocación tradicional del territorio, porque la mayor parte de la superficie provincial es paisaje de dehesa y su explotación continúa viva en la actualidad. Es más, el uso de los fitotopónimos sigue aún vigente a pesar de que es incuestionable el despoblamiento rural y el envejecimiento de la población en este tipo de paisajes poco productivos desde el punto de vista agro-industrial, pero no desde su valor ambiental.

El análisis realizado ha permitido constatar la importancia de los topónimos de carácter vegetal dentro de la toponimia extraída del MTN50 de la provincia de Salamanca, ya que suponen un $15 \%$ del total (1516 citas). Dentro de estas destaca que el $65 \%$ son pagos, topónimos menores que denominan espacios basándose en elementos del paisaje vegetal. Y, a su vez, el $49 \%$ de estos hacen referencia a especies y/o formaciones arbóreas, siendo relevante la presencia de encinas y robles. Es decir, aunque la fitotoponimia no sea el elemento más numeroso dentro del 
amplio abanico de topónimos que existen en la provincia de Salamanca, se trata de un componente de notable interés para interpretar el territorio.

Es significativo, y totalmente lógico en esta provincia, el elevado número de topónimos referidos a las dehesas (230), que supone un 15,2\% de todos los fitotopónimos, debido a que la explotación de las fincas se mantiene hasta la actualidad. De hecho, estos se localizan en aquellos espacios en los que la actividad tradicional es o ha sido el aprovechamiento en forma de dehesa, es decir, de tipo agro-silvo-pastoril. Como ejemplo de actividad actual de este territorio adehesado, y por citar solo algunos datos significativos, si atendemos al censo de la raza de lidia a fecha de 31 de diciembre de 2018 (MAPA, 2018), en la provincia de Salamanca hay inscritos 33208 animales, cifra que la coloca a la cabeza de las provincias españolas en la cría de este tipo de ganado. Así mismo, esta provincia ocupaba en 2013 el primer lugar en la producción de leña de Quercus ilex y el segundo puesto en la producción de Quercus pyrenaica. Según los datos ofrecidos por el Ministerio de Agricultura (MAPA, 2017) se gestionaba una producción de 133510 y 36873 toneladas de leña respectivamente, siendo el 99,5\% de esta cantidad de titularidad privada y solamente el 0,5\% proveniente de montes de carácter público. En concreto, en la provincia de Salamanca, estos espacios adehesados se localizan mayoritariamente en las comarcas agrarias del oeste y del sur, donde el sustrato geológico no permite que existan suelos lo suficientemente desarrollados para el uso agrícola: Vitigudino, Ledesma, Ciudad Rodrigo, La Fuente de San Esteban y Béjar.

Esta correlación entre territorio y topónimo ratifica la hipótesis de partida que se basaba en el posible ajuste entre la vegetación natural y la fitotoponimia tal y como ya se ha expuesto con anterioridad en los trabajos de Marco (2001, 2004) y Moll et al. (2017). Dicha correspondencia es muy elevada en el caso del binomio encina-roble/territorio, ya que presentan porcentajes de correlación del 68 \% y 74 \% respectivamente, entre la localización de estos topónimos y su área de distribución potencial. Y esta correlación no es mayor debido a la proximidad ecológica que tienen ambas especies, las cuales pueden aparecer mezcladas creando formaciones boscosas mixtas de quercíneas, especialmente en sus áreas transicionales. Incluso, desde el punto de vista del uso del suelo para un aprovechamiento adehesado siguiendo los patrones agro-silvo-pastoriles, las dos especies se consideraban adecuadas tanto para el ramoneo como para la producción de bellotas y de leña.

También se ha identificado una correlación elevada de los arbustos y pequeños árboles que forman parte de la orla espinosa de estos bosques, como son el madroño, el mostajo o el manzano en los robledales, mientras que las referencias al peral silvestre se encuentran tanto en encinares como en robledales. En cuanto a los matorrales, existe una gran correspondencia entre retamas, 
escobas/piornales y jarales con el área de distribución potencial de los encinares, así como de los brezales con los bosques de roble en las áreas más serranas.

Por otro lado, la correlación entre los topónimos referentes a los bosques de ribera y su localización en los valles fluviales es incuestionable, evidente y lógica desde la dinámica natural, pues todos estos fitotopónimos están asociados a un cauce, sobre todo en aquellos casos que cuentan con un caudal permanente, como en los ríos Tormes, Águeda y Huebra.

Todas estas conclusiones derivadas del análisis que se han realizado con anterioridad muestran cierta similitud con algunas de las investigaciones fitotoponímicas del entorno más cercano. Por ejemplo, en el trabajo de González y Sanz (2006) sobre toponimia de carácter vegetal de la provincia de Segovia, la encina y el roble melojo fueron dos de las cuatro especies más veces mencionadas; si bien es cierto que, en dicha investigación, así como en la desarrollada en el Poniente Granadino por Benítez et al. (2009), aparecía la vid como especie más veces identificada, cultivo que fue excluido de este estudio sobre Salamanca, como ya se indicó en la metodología. En esta última investigación, era la encina el segundo topónimo más mencionado, especie que también cuenta con un mayor número de referencias en el estudio que GarcíaVillaraco et al. (2011) Ilevaron a cabo sobre la provincia de Ciudad Real. Es decir, se observa que en algunos de los estudios sobre fitotoponimia realizados en provincias del centro y sur peninsular, los resultados se asemejan a los obtenidos en la provincia de Salamanca, destacando siempre la encina como árbol característico del paisaje vegetal ibérico.

Dentro del ámbito mediterráneo, en el estudio realizado por Grimalt et al. (2009) las citas toponímicas referidas a la vegetación que ellos identifican en la isla de Menorca desprenden unos resultados que son acordes a los obtenidos para la provincia de Salamanca. En este caso la encina es la segunda especie más mencionada por detrás de Erica arborea, siguiendo la tendencia de los estudios mencionados anteriormente. Si variamos el contexto climático, en los estudios realizados en el marco más próximo al dominio atlántico, donde los árboles de hoja caduca tienen mayor representación, el trabajo desarrollado por López y Cuevas (2011) pone de manifiesto la existencia de especies propias de estos climas denominando los lugares, como parece lógico y normal. Así, serán el roble, haya y rebollo los que adquieran mayor representación.

En conclusión, este trabajo permite identificar la estrecha relación existente en Salamanca entre la toponimia de carácter vegetal y la distribución potencial de algunas de las principales especies vegetales: la encina (Quercus ilex subp. ballota), el roble (Quercus pyrenaica), el mostajo (Sorbus aria) o el madroño (Arbutus unedo) presentan correlaciones muy elevadas entre sus diferentes topónimos y su presencia potencial en el territorio, mientras que con otros topónimos, esta relación no parece ser tan evidente. Estos resultados son equiparables con los obtenidos por los autores anteriormente citados. 
Del mismo modo, es conveniente poner de manifiesto el destacado papel que pueden tener los topónimos fósiles como memoria de paisajes pretéritos que permiten, entre otros aspectos, identificar procesos relacionados con los cambios de uso del suelo tal como indica Marco (2001, 2004).

De cara a futuros estudios, una línea de investigación que se podría desarrollar y complementaría la llevada a cabo sería el análisis de la distribución de fitotopónimos que no han sido incluidos en esta, como son dos de los cultivos más característicos de nuestro país, la vid y el olivo, puesto que trabajos similares han demostrado su elevada presencia en territorios próximos. Además, los topónimos aquí manejados son aquellos sobre los que no existe duda sobre su significado, por tanto, no hay que descartar que nuevas investigaciones desde el campo de la lingüística permitan incorporar algún otro a los ya manejados, pudiendo así variar ligeramente los resultados. Cuestión más compleja sería pretender analizar algunos de estos mismos topónimos, que son palabras de la lengua española, en territorios de Latinoamérica y Estados Unidos donde también se habla español y se emplean para denominar especies vegetales diferentes, propias de la flora neotropical.

Declaración responsable: Las/os autoras/es declaran que no existe ningún conflicto de interés en relación a la publicación de este artículo. Las tareas se han distribuido de la siguiente manera: Rubén Fernández Álvarez y Alejandro Gómez-Gonçalves se han encargado de la elaboración de la base de datos de los topónimos, así como de su georreferenciación. Miguel Ángel Luengo Ugidos se ha centrado en el análisis de la vegetación de la provincia de Salamanca para, posteriormente, entre los tres autores proceder al análisis de la distribución de los fitotopónimos y de su correspondencia con la vegetación potencial. Igualmente, los tres han participado en el análisis de los resultados, en la elaboración de la cartografía y en la redacción del texto. 


\section{Bibliografía}

Arroyo, F. (2010). Creciente interés geográfico por la toponimia. Estudios Geográficos, 268, 299-309. http://dx.doi.org/10.3989/estgeogr.0600

Alcaraz, A., \& Azcárate, M. (2005). Toponimia: Normas para el MTN25. Conceptos básicos y terminología. Madrid: Centro Nacional de Información Geográfica.

Benítez, G., González, M., \& Molero, J. (2009). Fitotopónimos y sinfitotopónimos del poniente granadino. Revista de dialectología y tradiciones populares, 64(2), 169-192. http://dx.doi.org/10.3989/rdtp.2009.019

Carrillo, A.F., Carrión, J.S., Fernández, S., \& Román, J.L. (2010). Toponimia y biogeografía histórica de plantas leñosas ibéricas, Murcia: EDITUM.

Doménech, A., \& Llorca, F.X. (2014). L'impacte en la toponímia de les activitats turístiques als espais naturals: el cas de la serra de l'Aitana (País Valencià). In Els noms de la vida quotidiana (pp. 2519-2527). Actes del XXIV Congrés Internacional d'ICOS sobre Ciències Onomàstiques. Generalitat de Catalunya, Departament de Cultura, Direcció General de Política Lingüística.

Fernández, R. (2014). Modelo de organización y evolución de paisajes ganaderos de montaña estudio comparativo de casos (valle medio y alto del río Saja; Sierras de Béjar y Candelario; Macizo de las Villuercas). Salamanca: Universidad de Salamanca.

Fidalgo, C., \& González, J.A. (2015). La evolución del paisaje natural a través de la toponimia: Lillo (La Mancha, Toledo. Cuadernos Geográficos, 54(2), 220-244. Retrieved from http://revistaseug.ugr.es/index.php/cuadgeo/article/view/2948/3881

García, A.J., Martínez, L.C., \& Prieto, I. (2018). Patrimonio cultural inmaterial en las Reservas de la Biosfera cantábricas: la recuperación de la toponimia en los Valles de Omaña y Luna (León). Estudios geográficos 79(284), 191-208. http://dx.doi.org/10.3989/estgeogr.201808

García-Villaraco, A., Pardo, M., \& Morales, R. (2011). Aportaciones a la fitoponimia de la provincia de Ciudad Real. Revista Folklore, 357, 4-23. Retrieved from http://media.cervantesvirtual.com/jdiaz/rf357.pdf

García, M. (1987). La vegetación en el paisaje del valle del Mera (Lugo). Ería, 14, 165-186.

González, F., \& Sanz, M. (2006). Toponimia de origen vegetal en la provincia de Segovia a partir de los datos del Catastro de Rústica. CT: Catastro, 56, 57-88. Retrieved from http://www.catastro.meh.es/documentos/publicaciones/ct/ct56/04-CATASTRO_56.pdf 
Gordón, M.D. (2011). La memoria de los lugares: la toponimia. PH: Boletín Andaluz del Patrimonio Histórico, 77, 90-91. Retrieved from

https://idus.us.es/xmlui/bitstream/handle/11441/67690/3108-3108-1-

PB.pdf? sequence $=1 \&$ is Allowed $=y$

Grimalt, M., Ordinas, A., \& Caldentey, J. (2009). El paisatge vegetal de Menorca a través de la fitotoponímia. Documents d'anàlisi geogràfica, 55, 93-116. Retrieved from https://ddd.uab.cat/pub/dag/02121573n55/02121573n55p93.pdf

Ingelmo, R. (2010). Localización y tratamiento de información histórica a través de la toponimia menor: utilidad del catastro de la riqueza rústica. In J. Ojeda, M.F. Pita \& I. Vallejo (Eds.), Tecnologías de la información geográfica: la información geográfica al servicio de los ciudadanos (pp. 199-213). Sevilla: Universidad de Sevilla.

Jiménez, R. (2007). El lenguaje no arbitrario: la łoponimia española. Interlingüística, 17, 547-552. Retrieved from https://estudiosinterlinguisticos.com/numero-17/

Llorente, A. (1991). Los topónimos españoles y su significado. Salamanca: Ediciones de la Universidad de Salamanca.

Llorente, A., \& Llorente, M.R. (2003). Toponimia salmantina. Salamanca: Diputación de Salamanca.

Llorente. J.M. (1995). La Sierra de Gata (El Rebollar-Agadones). In V. Cabero (Coord.), Salamanca y sus comarcas (pp. 313-320). Salamanca: Agedime SL- Editorial Mediterráneo.

Llorente, J.M. (2011). El valor indicador de los topónimos. El caso de la voz berrocal y sus variantes. Boletín de la Asociación de Geógrafos Españoles, 56, 59-77. Retrieved from https://www.age-geografia.es/ojs/index.php/bage/article/view/1344/1267

López, C., \& Cuevas, J. (2011). Árboles del ámbito de los bosques caducifolios en la toponimia del sistema ibérico septentrional. In J. Tort, M. Montagut (Eds.), Els noms en la vida quotidiana. Actes del XXIV Congrés internacional d'ICOS sobre Ciències Onomàstiques (pp .1880-1892). Barcelona: Generalitat de Catalunya. Departament de Cultura.

López, G. (2014). Guía de los árboles y arbustos de la Península Ibérica y Baleares. Madrid: Ediciones Mundi-Prensa.

Maldonado, J., Benito, M., Sánchez, R., \& Sáinz, H. (2002). Evolución reciente de las áreas de los bosques esclerófilos ibéricos. Cambios deducidos a partir de la cartografía forestal. In J. Charco (Coord.), La regeneración natural del bosque mediterráneo en la Península Ibérica (pp. 217236). Madrid: ARBA-DGCONA. 
MAPA (2017). Anuario estadístico forestal 2013. Madrid: Ministerio de Agricultura y Pesca, Alimentación y Medio Ambiente, Centro de Publicaciones.

MAPA (2018). Censo de la raza de Lidia 2018. In Ministerio de Agricultura, Pesca y Alimentación. Retrieved from https://www.mapa.gob.es/es/ganaderia/temas/zootecnia/razasganaderas/razas/catalogo/autoctona-fomento/bovino/lidia/iframe-ejemplo-arca.aspx

Marco, J.A. (2001). Assaig metodològic, per a la interpretació, sistematització i representació cartogàfica dels fitònims. Cuadernos de Geografía, 69-70, 53-74. Retrieved from http://roderic.uv.es/handle/10550/31237

Marco, J.A. (2004). Atles fitonímic d'Alacant. Alicante: Universitat d’Alacant.

Marco, J.A. (1985). La utilitat dels topònims: el casconcret de la Serra de Santa Pola. La Rella, 4, $29-35$.

Mateos, M.D. (1966). La España del Antiguo Régimen. Salamanca. Salamanca: Ediciones de la Universidad de Salamanca.

Membrado-Tena, J.C., \& Iranzo-García, E. (2017). Los nombres de lugar como elementos evocadores del paisaje histórico. Análisis de la toponimia de los núcleos de población de la cuenca del Vinalopó. Investigaciones Geográficas, 68, 191-207. http://rua.ua.es/dspace/handle/10045/72017

Moll, M.; Giménez, P., \& Marco, J.A. (2017): Els noms de lloc vinculats amb el medi físic i I'aprofitament dels recursos naturals: la Vall de Laguar. In E. Casanova (Ed.), Onomàstica Románica: Antroponímia dels expòsits i etimología toponímica, especialmente de València (pp. 649-660). València: Editorial Denes.

Molina, F. (2012). La toponimia como medio de información geográfica: el caso de los fitotopónimos. Biblio 3W, Revista Bibliográfica de Geografía y Ciencias Sociales. XVII(982). Retrieved from http://www.ub.edu/geocrit/b3w-982.htm

Morales, P., \& Morales, A. (2000). Análisis de los recursos productivos de las dehesas salmantinas. Actas del $7^{\circ}$ Congreso de Economía Regional de Castilla y León, 2000, 54, 367378.

Ordinas, A., \& Binimelis, J. (2013). La caracterización del paisaje de Menorca a través de la toponimia. Investigaciones Geográficas, 60, 155-169. http://dx.doi.org/10.14198/INGEO2013.60.09

Panareda, J. M. (2011). Aproximación a la fitotoponímia del Montseny (Catalunya). In J. Tort, M. Montagut (eds.), Els noms en la vida quotidiana. Actes del XXIV Congrés internacional d'ICOS 
sobre Ciències Onomàstiques (pp. 3072-3079). Barcelona: Generalitat de Catalunya. Departament de Cultura.

Pérez, A. (1922). Sierras y Campos Salamanquinos. Salamanca.

Riesco, P. (2010). Nombres en el paisaje: la toponimia, fuente de conocimiento y aprecio del territorio. Cuadernos Geográficos, 46, 7-34.

Rivas-Martínez, S. (2011). Mapa de series, geoseries y geopermaseries de vegetación de España: [Memoria del mapa de vegetación potencial de España]. Parte II. Itinerageobotánica, 18(1), 5424.

Román, J. (2013). La flora y su terminología en la provincia de Jaén: Fitotoponimia y Dialectología. UNED: Madrid.

Sancho, I., \& Fidalgo, C. (2004). Evolución del paisaje vegetal en el siglo XX a partir del Catastro de la Propiedad Rústica (Comarca del Alberche, Madrid). CT: Catastro, 52, 55-84.

Sanz, M.,\& González, F. (2006). Toponimia de origen vegetal en la provincia de Segovia y su sentido ecológico y etnobotánico. Lazaroa, 27, 103-125.

Sanz, M., \& Villar, L. (2012). Topónimos mayores y menores de origen vegetal en el Alto Aragón. Luenga y Fablas, 15-16, 99-117.

Sousa, A., \& García-Murillo, P. (2001). Can place names be used as indicators of landscape changes? Applicationtothe Doñana Natural Park (Spain). LandscapeEcology, 16, 391-406.

Torres, G.J. (2016). Fitotoponimia en Sierra Mágina. Sumuntán: anuario de estudios sobre Sierra Mágina, 34, 165-186.

Tort, J. (2000). Toponimia y territorio. Los nombres de los núcleos de población de la comarca del Baix Camp, Tarragona, desde una perspectiva onomasiológica. Scripta Nova, 67. Retrieved from http://www.ub.edu/geocrit/sn-67.htm

Tort, J. (2006). Elsnoms de lloc i el territori: la toponímia des de la geografía. In E. Mallorqui (Ed.), Toponímia, paisatge i cultura. Els noms de lloc des de la lingüística, la geografia i la historia (pp. 69-98). Gerona: Documenta Universitaria.

Tort, J. (2003). A propòsit de la relació entre toponímia i geografia: el principi de 'significativitat territorial'. Butlletí Interior de la Societatd'Onomàstica, 94-95, 675-688.

Tort, J. (2001). La toponímiacom a camp de coneixementinterdisciplinari: Algunes bases teòriques i epistemològiques per a l'estudidelsnoms de lloc. Scripta Nova, 86. Retrieved from http://www.ub.edu/geocrit/sn-86.htm 
Valenzuela, E. (2010). ¿Es posible aprender Geografía a través de la toponimia? Investigación Universitaria Multidisciplinaria: Revista de Investigación de la Universidad Simón Bolívar, 9, 1626. 